\title{
Knowledge Licensing in a Model of R\&D-Driven Endogenous Growth
}

\author{
Vahagn Jerbashian*
}

\begin{abstract}
I model knowledge (patent) licensing and evaluate intellectual property regulation in an endogenous growth framework where the engine of growth is in-house R\&D performed by high-tech firms. I show that high-tech firms innovate more and economic growth is higher when there is knowledge licensing, and when intellectual property regulation facilitates excludability of knowledge, than when knowledge is not excludable and there are knowledge spillovers among high-tech firms. However, the number of high-tech firms is lower, and welfare is not necessarily higher, when there is knowledge licensing than when there are knowledge spillovers.
\end{abstract}

Keywords: Knowledge Licensing; In-house R\&D; Intellectual Property Regulation; Endogenous Growth; Welfare

JEL classification: O31; O34; L16; L50; O41

\footnotetext{
*Departament d'Economia and CREB, Universitat de Barcelona, and CERGE-EI. Correspondence address: Avenue Diagonal 696, 08034 Barcelona, Spain. E-mail: vahagn.jerbashian@ub.edu. Phone: +34934034890 .

CERGE-EI is a joint workplace of the Center for Economic Research and Graduate Education, Charles University in Prague, and the Economics Institute of Academy of Sciences of the Czech Republic.
} 


\section{Introduction}

A number of growth models treat private firms' intentional investments in R\&D as the driver of long-run growth and welfare (e.g., Romer, 1990, Aghion and Howitt, 1992). These models assume that there are knowledge spillovers in the R\&D process and that R\&D builds on a pool of knowledge. In this sense, these growth models abstract from the role of knowledge (patent) licensing and from the details about the exchange of knowledge in the economy. Nevertheless, licensing and citing patents is common in high-tech industries and seems to play a significant role for innovation (e.g., Anand and Khanna, 2000, Shapiro, 2001, Arora and Gambardella, 2010). Current high-profile examples include licensing agreements and patent citations among product market rivals such as Google, Microsoft, and Apple Inc.

In this paper, I present an endogenous growth model where high-tech firms engage in in-house $R \& D$ which then drives long-run growth. High-tech firms have exclusive rights to their product type. In a high-tech firm, the innovation enhances firm/productspecific knowledge, which reduces the firm's marginal costs or increases the quality of its product. High-tech firms finance their R\&D expenditures from operating profits. They set prices and compete strategically in their output market. My point of departure is that I model knowledge (patent) licensing among high-tech firms. The knowledge generated in a high-tech firm cannot be used for free, since intellectual property regulation facilitates its excludability (i.e., it favors patents). However, it can be licensed. Given that each high-tech firm produces a distinct type of good, for such a firm the knowledge of other high-tech firms is complementary to its own. If a high-tech firm licenses the knowledge of another, it can combine that knowledge with its own and improve its in-house $R \& D$ process, since the latter builds on the knowledge that the firm possesses.

I evaluate intellectual property regulation and contrast the inference from this setup to the inference from a setup where intellectual property regulation does not facilitate excludability and there are knowledge spillovers among high-tech firms. I also show how market concentration and the intensity of competition, as measured by the elasticity of substitution between high-tech goods, can matter for innovation in the high-tech industry and aggregate performance in both setups.

I show that innovation in the high-tech industry, economic growth, and welfare, are higher when there is knowledge licensing than when there are knowledge spillovers. Innovation and growth are higher when there is knowledge licensing because firms appropriate the benefits from their R\&D more in this case. In turn, welfare is higher because these dynamic gains prevail over the static losses in terms of within-period output.

In both setups that I consider, innovation in the high-tech industry and economic growth increase with the number of high-tech firms and the intensity of competition. The drivers behind these results are the relative price distortions, which are due to price setting 
by high-tech firms. These distortions adversely affect the demand for high-tech goods. Given that high-tech firms interact strategically in the output market, a higher number of firms and more intensive competition imply lower mark-ups and lower distortions. This increases the demand for high-tech goods and implies higher output and investments in R\&D in the high-tech industry. ${ }^{1}$

Finally, I endogenize the number of high-tech firms assuming cost-free entry. Again, innovation in the high-tech industry and economic growth are higher when there is knowledge licensing than when there are knowledge spillovers. This happens, however, at the expense of the number of high-tech firms (or the variety of high-tech goods). The number of high-tech firms is lower when there is knowledge licensing than when there are knowledge spillovers. Because of this, welfare is not necessarily higher when there is knowledge licensing.

I also show that increasing the intensity of competition reduces the number of firms in both setups. This has no effect, however, on innovation in the high-tech industry and economic growth.

This paper is related to the endogenous growth literature (e.g., Romer, 1990, Aghion and Howitt, 1992, Smulders and van de Klundert, 1995), where the positive growth of the economy on a balanced growth path is a result of technological and preference factors. In particular, it is related to studies which, in an endogenous growth framework, suggest how the aggregate performance can be affected by imperfect competition in an industry where the firms engage in in-house R\&D (e.g., Peretto, 1996, van de Klundert and Smulders, 1997). It contributes to these streams of studies while showing how knowledge licensing in such an industry can affect innovation, economic growth, and welfare.

Several studies evaluate intellectual property regulation from the perspective of the duration of patents in the standard variety-expansion frameworks (e.g., Judd, 1985, Futagami and Iwaisako, 2007). There are also a number of studies that model knowledge and technology licensing in the standard Schumpeterian growth framework and show how intellectual property regulation and international technology licensing can affect innovation and growth (e.g., O'Donoghue and Zweimüller, 2004, Yang and Maskus, 2001, Tanaka, Iwaisako, and Futagami, 2007). In these studies, licensing happens between incumbents and entrants given that in the standard Schumpeterian growth framework incumbents have no incentives to innovate. Licensing does not explicitly aid the R\&D process and licenses are essentially permits for production. In order to maintain incentives for licensing, these studies assume that either licensors and licensees (incumbents and entrants) collude in the product market, or licensees can access a larger market (e.g., one of the countries bans FDI). The share in collective profits and licensing fees compen-

${ }^{1}$ O'Donoghue and Zweimüller (2004) have a similar result in a Schumpeterian growth model. Vives (2008) shows that such a result can also hold in partial equilibrium for various types of demand functions. The positive relation between innovation and competitive pressure is consistent with empirical findings of, for example, Blundell, Griffith, and van Reenen (1999). 
sate incumbents' loss of the product market (and costs of technology transfer) and are either exogenous or exogenously determined by intellectual property regulation. In contrast, this paper has a non-tournament framework where incumbents engage in in-house R\&D, which improves their productivity or the quality of their product. Incumbents innovate because it enables the stealing market of share, and licensing happens among incumbents. Firms have an incentive to license knowledge from other firms because that aids their R\&D process. The intellectual property regulation affects the excludability of knowledge and its market structure. License fees are determined by the structure of the market for knowledge and supply and demand conditions. To that end, the framework and analysis of this paper can be thought of as complementary.

There is also a large body of firm- and industry-level studies that analyze the implications of patent licensing, patent consortia or pools, and knowledge exchange among firms on innovation and market conduct (e.g., Gallini and Winter, 1985, Katz and Shapiro, 1985, Faulí-Oller and Sandonís, 2002, Arora and Fosfuri, 2003). This paper analyzes such issues at the aggregate level in a dynamic general equilibrium framework, which assumes an undistorted market for knowledge/patents. This assumption allows for tractable inference. In turn, the dynamic general equilibrium framework endogenizes the growth rate of the economy and the effect of knowledge licensing on, for example, the interest rate which affects the incentives to perform $\mathrm{R} \& \mathrm{D}$. Licensing in this paper ceteris paribus motivates R\&D. This implies a higher growth rate and higher rate of interest which reduces the incentives to perform R\&D.

The next section introduces the model. Section 3 analyzes the features of dynamic equilibrium. Section 4 concludes. The proofs of the results are offered at the end of the paper.

\section{The Model}

\section{Households}

The economy is populated by a continuum of identical and infinitely lived households of mass one. The representative household is endowed with a fixed amount of labor $L$. It inelastically supplies its labor to firms which produce final goods and to high-tech firms. The household has a standard CIES utility function with an inter-temporal substitution parameter $1 / \theta$ and discounts the future streams of utility with rate $\rho(\theta, \rho>0)$. The utility gains are from the consumption of amount $C$ of final goods. The lifetime utility of the household is

$$
U=\int_{0}^{+\infty} \frac{C_{t}^{1-\theta}-1}{1-\theta} \exp (-\rho t) d t
$$


The household maximizes its lifetime utility subject to a budget constraint:

$$
\dot{A}=r A+w L-C
$$

where $A$ is the household's asset holdings $[A(0)>0], r$ and $w$ are the market returns on its asset holdings and labor supply.

The rule that follows from the household's optimal problem is the standard Euler equation:

$$
\frac{\dot{C}}{C}=\frac{1}{\theta}(r-\rho) .
$$

This, together with the budget constraint, describes the paths of the household's consumption and assets.

\section{Final Goods}

Final goods, $Y$, are homogeneous. The household's demand for final goods is served by a representative producer. The production of final goods requires labor and $X$, which is a CES composite of high-tech goods $\left\{x_{i}\right\}$ with an elasticity of substitution $\varepsilon(\varepsilon>1)$.

The production of the final goods has a Cobb-Douglas technology and is given by

$$
Y=X^{\sigma} L_{Y}^{1-\sigma}
$$

where

$$
X=\left(\sum_{i=1}^{N} x_{i}^{\frac{\varepsilon-1}{\varepsilon}}\right)^{\frac{\varepsilon}{\varepsilon-1}}
$$

$L_{Y}$ is the share of the labor force employed in final goods production, $N$ is the number of high-tech goods, and $1>\sigma>0 .^{2}$

For ease of exposition, the problem of the representative final goods producer is divided into two steps. In the first step, the representative producer decides on the optimal combination of $L_{Y}$ and $X$ in $Y$ and in the second step it decides on the optimal amounts of high-tech goods $x$ in $X$.

Therefore, in the first step the representative producer solves the following problem:

$$
\max _{L_{Y}, X}\left\{Y-w L_{Y}-P_{X} X\right\}
$$

where $P_{X}$ is the private marginal value of $X$ and $Y$ is the numeraire. The optimal rules that follow from this problem describe the final goods producer's demand for labor and

${ }^{2}$ I allow $N$ to be real number in order to avoid complications arising from integer constraints. 
the optimal amount of $X$ in the production of $Y$ :

$$
\begin{aligned}
& w L_{Y}=(1-\sigma) Y, \\
& P_{X} X=\sigma Y .
\end{aligned}
$$

In the second step, the producer solves:

$$
\max _{\left\{x_{i}\right\}_{i=1}^{N}}\left\{P_{X} X-\sum_{i=1}^{N} p_{x_{i}} x_{i}\right\},
$$

where $p_{x}$ is the price of $x$. This implies that the demand for a high-tech good $j(j=$ $1, \ldots, N)$ is given by

$$
x_{j}=X\left(\frac{P_{X}}{p_{x_{j}}}\right)^{\varepsilon} .
$$

From this expression follow two equilibrium conditions:

$$
\begin{aligned}
& P_{X} X=\sum_{i=1}^{N} p_{x_{i}} x_{i}, \\
& P_{X}=\left(\sum_{i=1}^{N} p_{x_{i}}^{1-\varepsilon}\right)^{\frac{1}{1-\varepsilon}},
\end{aligned}
$$

where (7) implies that there is no waste and (8) implies that $P_{X}$ is an index of $p_{x}$.

\section{High-Tech Goods}

Each high-tech firm owns a design of distinct high-tech good $x$, which it produces. The production of a high-tech good requires labor input $L_{x}$. The production function of a high-tech good $x$ is given by

$$
x=\lambda L_{x}
$$

where $\lambda$ measures the producer's knowledge of the production process or the quality of the high-tech good. This knowledge is firm/product-specific since each high-tech firm produces a distinct good.

High-tech firms are price setters in their output market and discount their future profit streams $\pi$ with the market interest rate $r$. I assume that high-tech firms cannot collude in the output market.

\section{In-House R\&D}

High-tech firms can engage in R\&D for accumulating knowledge and increasing $\lambda$. This can be interpreted as a process innovation that increases productivity (the firms are able to produce more of $x$ ), or as a quality upgrade (the firms are able to produce the same 
amount of higher quality $x$ ). Knowledge is not a rival input so that, potentially, it can be used at the same time in multiple places/firms.

In this section, I offer two different settings for the R\&D process. The differences stem from how knowledge is exchanged among high-tech firms. In both cases, I assume that the firms cannot collude and stop innovating (for example, because of antitrust regulation or non-sustainability of collusion). ${ }^{3}$

Hereafter, when appropriate, for ease of exposition, I describe the properties of the high-tech industry taking, as an example, a high-tech firm $j$. In order to improve its knowledge $\lambda_{j}$ the firm needs to hire researchers/labor $L_{r_{j}}$. Researchers use the current knowledge of the firm in order to create better knowledge.

Knowledge Licensing: This is the benchmark setup, and I call it S.1. Knowledge in this setup can be licensed. If high-tech firm $j$ decides to license knowledge from other high-tech firms, its researchers combine that knowledge with the knowledge available in the firm, in order to produce new knowledge. The knowledge available in the firm is an essential input in the R\&D of the firm. Moreover, it is the only essential input. This implies that the high-tech firm does not need to acquire knowledge from other firms in order to advance its own. However, it needs to have its own knowledge in order to build on it. This is in line with the fact that high-tech firms produce distinct goods.

I assume that the in-house $R \& D$ process is given by

$$
\dot{\lambda}_{j}=\xi\left[\sum_{i=1}^{N}\left(u_{i, j} \lambda_{i}\right)^{\alpha}\right] \lambda_{j}^{1-\alpha} L_{r_{j}}
$$

where $\xi$ is an exogenous efficiency level $(\xi>0), u_{i, j}$ is the share of knowledge of firm $i$ that firm $j$ licenses, $u_{j, j} \equiv 1$, and $1>\alpha>0$.

Intellectual property regulation facilitates excludability of knowledge and grants bargaining power to the licensors in the sense that they can make a 'take it or leave it' offer to licensees. In turn, license contracts do not allow for sub-licensing. ${ }^{4}$

It can be shown that in (10) the elasticity of substitution between the different types of knowledge that the high-tech firm licenses is equal to $1 /(1-\alpha)$. It can also be shown that the elasticity of substitution between the high-tech firm's knowledge and any knowledge that it licenses is lower than $1 /(1-\alpha)$. This restates the importance of the firm's knowledge for its $R \& D$ process.

In this R\&D process, the productivity of researchers increases linearly with knowledge licensed from an additional high-tech firm because of summation. Such a formulation can be justified if there are significant complementarities among the knowledge of high-tech

\footnotetext{
${ }^{3}$ Appendix E.1 offers a setup where firms cooperate in R\&D and compete in the product market.

${ }^{4}$ I also need to assume that patent infringements are detectable. This seem to be a plausible assumption given the recent history of the high number of patent infringement lawsuits in high-tech industries.
} 
firms. ${ }^{5}$ Further, it might seem brave to assume that R\&D in a single firm can have non-decreasing returns. ${ }^{6}$ This assumption allows the focus to be on the effect of market structure of the high-tech industry on innovation in that industry through competitive pressure. It can be relaxed by setting $u_{j, j} \equiv 0$ in square brackets in (10). In such a case, in this model knowledge licensing (or exchange of knowledge) is a necessary condition to ensure non-decreasing returns to $\mathrm{R} \& \mathrm{D}$ and positive growth in the long-run (for further details, see Appendix E.2). The R\&D process (10) can also be viewed as a simplification leading to tractable results. It ensures that there is a balanced growth path, for example. ${ }^{7}$

One way to think about this setup is that each high-tech firm can license the patented knowledge of other firms in order to generate its own patented knowledge, which helps to improve its production or output. The firm does not use the knowledge that it licensed directly in the production of its good, because that knowledge needs to be combined with its own knowledge, and that requires investments in terms of hiring researchers and time. The latter seems plausible for technologically sophisticated (e.g., high-tech) goods.

Knowledge Spillovers: In this setup, S.2, there are knowledge spillovers among hightech firms. In high-tech firm $j$, the researchers combine the knowledge that spills over from other high-tech firms with the knowledge available in the firm, while generating new knowledge. In order to maintain symmetry, I also assume that the researchers do not fully internalize the use of the current knowledge available in the firm, and have external benefits from it. Similar to the previous setup, this assumption allows the focus to be on the effect of market structure of the high-tech industry on innovation through competitive pressure.

The $R \& D$ process is given by

$$
\dot{\lambda}_{j}=\xi \tilde{\Lambda} \lambda_{j}^{1-\alpha} L_{r_{j}}
$$

where I assume that in equilibrium $\tilde{\Lambda}$ is equal to

$$
\tilde{\Lambda}=\sum_{i=1}^{N} \lambda_{i}^{\alpha}
$$

An interpretation for this case is that intellectual property regulation does not enforce

\footnotetext{
${ }^{5}$ Rivera-Batiz and Romer (1991) and Grossman and Helpman (1995) have a similar additive structure for knowledge in the R\&D process in the context of knowledge spillovers among countries. Peretto (1998a b) has a similar structure in the context of knowledge spillovers within an industry.

${ }^{6}$ In this respect, an example of a high-tech firm might be IBM, which started with tabulating machines a century ago and reached the point of producing supercomputers.

${ }^{7}$ This formulation of the R\&D process leads to scale effects which are contentious (Jones, 1995, 2005, Jones and Romer, 2010). The mechanisms behind the main results of this paper are based on factor allocations. Therefore, as shown in Appendix E.5 and Appendix E.6, the results might not generalize in the "second generation" growth models, but can generalize in the "third generation" models. I maintain the current framework for its analytical simplicity.
} 
excludability and firms cannot maintain secrecy. Another possible interpretation is that there is a market for knowledge, and intellectual property regulation grants the bargaining power to the potential licensees, so that they have the right to make a 'take it or leave it' offer. The licensees under this assumption receive the knowledge at no cost (i.e., there are spillovers) if the supply of knowledge is not elastic. The supply is necessarily inelastic if licensors do not have trade-offs associated with licensing knowledge. It seems natural to assume that once knowledge is created, its supply entails virtually no costs. There would then be no trade-offs if licensors do not take into account that the knowledge they license is used for stealing business: the licensees use it in order to reduce their prices and steal market share. In this line of literature, it is common to assume that the originators of knowledge spillovers do not internalize the effect of spillovers on others' R\&D and production processes. In the frames of this model, this assumption is necessary in order to give such a market-based interpretation to knowledge spillovers. The choice of the interpretation is a matter of taste.

In practice, licensing and spillovers tend to coexist in high-tech industries. These setups are then polar cases. This sharpens the comparison of inference (see Appendix E.3 for a setup where there are knowledge licensing and spillovers).

Similar to $\lambda$, the design of a high-tech good can be viewed as knowledge/patent. It needs to be assumed that (at least for some time) the knowledge about the design of high-tech goods cannot be used by other firms without appropriate compensation, in order to guarantee that high-tech firms have incentives to innovate. Any high-tech firm, nevertheless, could sell the design of its good at market value: the discounted sum of profit streams. Therefore, the assumption that intellectual property regulation enforces excludability of knowledge $\lambda$ and grants the bargaining power to the licensors seems to be more consistent in such a setup. ${ }^{8}$

\section{Optimal Problem}

The revenues of high-tech firm $j$ are gathered from the supply of its good $\left(x_{j}\right)$ and when there is knowledge licensing from the supply of its knowledge $\left(u_{j, i} \lambda_{j} ; \forall i \neq j\right)$. The costs are the labor compensations and license fees when there is knowledge licensing. The profits of high-tech firm $j$ are given by

$$
\begin{aligned}
\pi_{j} & =p_{x_{j}} x_{j}-w\left(L_{x_{j}}+L_{r_{j}}\right) \\
& +\left[\sum_{i=1, i \neq j}^{N} p_{u_{j, i} \lambda_{j}}\left(u_{j, i} \lambda_{j}\right)-\sum_{i=1, i \neq j}^{N} p_{u_{i, j} \lambda_{i}}\left(u_{i, j} \lambda_{i}\right)\right],
\end{aligned}
$$

\footnotetext{
${ }_{8}^{8}$ It might be insightful to assess the impact of intellectual property regulation which affects both the excludability of $\lambda$ and the duration of rights/patent on $x$. This is left for future research.
} 
where the term in square brackets appears when there is knowledge licensing, and $p_{u_{j, i} \lambda_{j}}$ and $p_{u_{i, j} \lambda_{i}}$ are the license fees for $u_{j, i} \lambda_{j}$ and $u_{i, j} \lambda_{i}$.

The high-tech firm maximizes the present discounted value $V_{j}$ of its profit streams. For brevity, I assume that high-tech firms choose the prices of their products and in that sense engage in a generalized type of Bertrand competition (see Jerbashian, 2014, for Cournot competition). Therefore, the problem of high-tech firm $j$ is

$$
\begin{aligned}
& V_{j}(\bar{t})=\max _{p_{x_{j}}, L_{r_{j}},\left\{u_{j, i}, u_{i, j}\right\}_{i=1 ;(i \neq j)}^{N}}\left\{\int_{\bar{t}}^{+\infty} \pi_{j}(t) \exp \left[-\int_{\bar{t}}^{t} r(s) d s\right] d t\right\} \\
& \text { s.t. } \\
& (6),(9),(13), \text { and either (10) or (11), }
\end{aligned}
$$

where $\bar{t}$ is the entry date and $\lambda_{j}(\bar{t})>0$ is given.

The solution of the optimal problem implies that the supply of high-tech good $x_{j}$ and the demand for labor for R\&D are given by

$$
\begin{aligned}
& w=\lambda_{j} p_{x_{j}}\left(1-\frac{1}{e_{j}}\right), \\
& w=q_{\lambda_{j}} \frac{\dot{\lambda}_{j}}{L_{r_{j}}}
\end{aligned}
$$

where $e_{j}$ is the elasticity of substitution between high-tech goods perceived by the hightech firm and $q_{\lambda_{j}}$ is the shadow value of knowledge accumulation.

It can be shown that

$$
e_{j}=\varepsilon-\left[\frac{(\varepsilon-1) p_{x_{j}}^{1-\varepsilon}}{\sum_{i=1}^{N} p_{x_{i}}^{1-\varepsilon}}\right] .
$$

The term in square brackets in (16) measures the extent of strategic interactions among high-tech firms, which create a wedge between $e$ and the actual elasticity of substitution $\varepsilon$. Therefore, it measures some of the distortions in the economy which stem from imperfect competition with a finite number of high-tech firms. The term in square brackets and these distortions tend to zero when the number of firms increases.

In the case when there is knowledge licensing, the returns on $R \& D$ are given by

$$
\frac{\dot{q}_{\lambda_{j}}}{q_{\lambda_{j}}}=r-\left(\frac{e_{j}-1}{e_{j}} \frac{p_{x_{j}}}{q_{\lambda_{j}}} L_{x_{j}}+\frac{\partial \dot{\lambda}_{j}}{\partial \lambda_{j}}+\sum_{i=1, i \neq j}^{N} \frac{p_{u_{j, i} \lambda_{j}} u_{j, i}}{q_{\lambda_{j}}}\right)
$$

where the first term in brackets is the benefit from accumulating knowledge in terms of increased output. The second term is the benefit in terms of higher amount of knowledge 
available for subsequent $R \& D$ :

$$
\frac{\partial \dot{\lambda}_{j}}{\partial \lambda_{j}}=\xi\left[1+(1-\alpha) \sum_{i=1, i \neq j}^{N}\left(\frac{u_{i, j} \lambda_{i}}{\lambda_{j}}\right)^{\alpha}\right] L_{r_{j}} .
$$

The third term is the benefit in terms of increased amount of knowledge that can be licensed.

The demand for, and the supply of knowledge, in this case are given by

$$
\begin{aligned}
& p_{u_{i, j} \lambda_{i}}=q_{\lambda_{j}} \xi \alpha\left(\frac{\lambda_{j}}{u_{i, j} \lambda_{i}}\right)^{1-\alpha} L_{r_{j}}, \forall i \neq j, \\
& u_{j, i}=1, \forall i \neq j
\end{aligned}
$$

which means that the firm has a downward sloping demand for knowledge and licenses (supplies) all its knowledge.

In the case when there are knowledge spillovers among high-tech firms, the returns on R\&D are given by (17) but

$$
p_{u_{j, i} \lambda_{j}}=0, \forall i
$$

and

$$
\frac{\partial \dot{\lambda}_{j}}{\partial \lambda_{j}}=\xi(1-\alpha)\left[\sum_{i=1}^{N}\left(\frac{\lambda_{i}}{\lambda_{j}}\right)^{\alpha}\right] L_{r_{j}}
$$

The first expression means that the licensees receive knowledge (patents) for free. In turn, there is a difference between (18) and (22) because when there is knowledge licensing the returns to $R \& D$ are fully appropriated within high-tech firms.

The expression for the price of knowledge (19) indicates that the licensees pay a fixed fee for it. The fee is equal to their marginal valuation of the knowledge that they acquire. This valuation includes all future benefits from using that knowledge for augmenting their current knowledge. Therefore, the licensors appropriate all the benefit from licensing knowledge (i.e., they make the 'take it or leave it' offer). With a continuous accumulation of knowledge, as given by (10), at each and every instant the licensees acquire new knowledge at a fixed fee.

From (19) it follows that $p_{u_{j, i} \lambda_{j}}$ declines with $\lambda_{j}$. It is clear from (17) that I have assumed that the firm treats $p_{u_{j, i} \lambda_{j}}$ as exogenous and does not take into account this effect while accumulating knowledge. In this sense, I focus on a perfect market for knowledge where the price of knowledge is equal to its marginal product and the licensors appropriate all benefits.

In the frames of this model, the assumption that the licensors of knowledge do not take into account that their knowledge is used for stealing business amounts to assuming that firm $j$ takes $q_{\lambda_{i}}$ as exogenous for any $i$ different than $j$. This is in line with assuming that it takes $p_{u_{j, i} \lambda_{j}}$ as exogenous (see for the case when it takes into account $p_{u_{j, i} \lambda_{j}}$ Appendix 
E.4).

Finally, in equilibrium there is no difference if high-tech firms license their knowledge in return to wealth transfer or knowledge of other firms. Therefore, knowledge licensing among high-tech firms can also be thought to resemble patent consortia and cross-licensing. ${ }^{9}$

\section{Firm Entry}

I focus on two regimes of entry into the high-tech industry. In the first regime there are exogenous barriers to entry (i.e., there is no entry) and all firms in the market are assumed to have entered at $t=0$. In the second regime there are no barriers to entry. Moreover, entry entails no costs (for a setup with endogenous sunk costs, see Jerbashian, 2014, 2015).

\section{Features of the Dynamic Equilibrium}

I restrict the attention to a symmetric equilibrium in the high-tech industry, and denote the growth rate of a variable $Z$ by $g_{Z}$. For subsequent analysis it is useful to define an indicator function $I_{S .2}^{1}$ as

$$
I_{S .2}^{1}=\left\{\begin{array}{l}
1 \text { for } S .2, \\
0 \text { otherwise } .
\end{array}\right.
$$

From (10), (11), and (12) it follows that the growth rate of knowledge/productivity in both setups can be written as

$$
g_{\lambda}=\xi N L_{r}
$$

The rate of return on knowledge accumulation can be derived from the optimal rules of the high-tech firm (14), (15), and (17)-(22). It is given by

$$
g_{q_{\lambda}}=r-g_{\lambda}\left(\frac{L_{x}}{L_{r}}+1-\alpha I_{S .2}^{1}\right)
$$

This expression determines the allocation of labor to $R \& D$ in a high-tech firm relative to the allocation of labor to production. This ratio does not (explicitly) depend on competitive pressure in the high-tech industry because high-tech firms decide on the division of labor between production and R\&D internally and $L_{x}$ and $L_{r}$ are paid the same wage.

From the high-tech firm's demand for labor for production (14), the representative final goods producer's optimal rules (4)-(5), and the relation between $P_{X} X$ and $p_{x} x(7)$

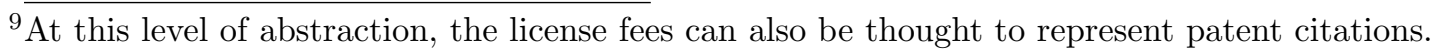


follows a relationship between $N L_{x}$ and $L_{Y}$ :

$$
N L_{x}=\frac{\sigma}{1-\sigma} b L_{Y}
$$

where

$$
\begin{aligned}
& b=\frac{e-1}{e}, \\
& e=\varepsilon-\frac{\varepsilon-1}{N} .
\end{aligned}
$$

This relationship takes into account the effect of price setting by high-tech firms. According to (26) and (27), $L_{Y} / N L_{x}$ declines with the number of firms $N$ and $\varepsilon$. This is because increasing $N$ and $\varepsilon$ reduces mark-ups and the relative price of $x$, which increases $N L_{x}$. Meanwhile, final goods producers substitute $X$ for $L_{Y}$ which reduces $L_{Y}$.

The relationship between $N L_{x}$ and $L_{Y}(25)$ together with the labor market clearing condition,

$$
L=L_{Y}+N\left(L_{x}+L_{r}\right),
$$

implies a relationship between $N L_{x}$ and $N L_{r}$ :

$$
N L_{x}=D\left(L-N L_{r}\right)
$$

In this expression, $D$ is equal to

$$
D=\frac{\sigma(e-1)}{e-\sigma}
$$

It measures the effect of competitive pressures in the high-tech industry on allocations of labor force.

In the final goods market it must be that

$$
Y=C{ }^{10}
$$

\section{Entry Regime 1: Barriers to Entry}

I take $N>1$ and allow profits $\pi$ in (13) to be negative. This is needed in order to characterize the behavior of growth rates and allocations for any $N>1$ and $\varepsilon$. It can be supported by subsidies, for example.

Let the consumers be sufficiently patient so that $\theta \geq 1$, which is a standard stability condition in multi-sector endogenous growth models and seems to be the empirically

\footnotetext{
${ }^{10}$ The main innovation of this paper is that it models knowledge licensing among high-tech firms. In the remainder of the text, I highlight the main innovation and its implications. The remainder of the properties of the framework can be found well characterized in Smulders and van de Klundert (1995), van de Klundert and Smulders (1997), Peretto (1998a b), Peretto and Smulders (2002), amongst others.
} 
relevant case. Moreover, let the following parameter restriction hold for any $N$ :

$$
\xi D L>\rho .
$$

This inequality ensures that the inter-temporal benefit from allocating labor force to R\&D outweighs its cost. It is a necessary condition for having an interior solution for labor force allocation to $\mathrm{R} \& \mathrm{D}$. The following proposition offers equilibrium labor force allocations and growth rates. I use $N E$ superscript to denote the case when there is no entry.

Proposition 1. In decentralized equilibrium in both S.1 and S.2 setups, the economy makes a discrete jump to a balanced growth path where labor force allocations and growth rates of final output and knowledge/productivity are given by

$$
\begin{aligned}
& N L_{r}^{N E}=\frac{1}{\xi} \frac{\xi D L-\rho}{(\theta-1) \sigma+\alpha I_{S .2}^{1}+D}, \\
& N L_{x}^{N E}=D\left(L-N L_{r}^{N E}\right), \\
& L_{Y}^{N E}=L-N L_{x}^{N E}-N L_{r}^{N E},
\end{aligned}
$$

and

$$
\begin{aligned}
& g_{Y}^{N E}=\sigma g_{\lambda}^{N E} \\
& g_{\lambda}^{N E}=\frac{\xi D L-\rho}{(\theta-1) \sigma+\alpha I_{S .2}^{1}+D}
\end{aligned}
$$

The interaction between $\alpha$ and $I_{S .2}^{1}$ measures the extent of non-appropriated returns on $\mathrm{R} \& \mathrm{D}$ in the case when there are knowledge spillovers compared to the case when there is knowledge licensing. Clearly, the growth rates of knowledge and final output, $g_{\lambda}^{N E}$ and $g_{Y}^{N E}$, decline with $\alpha I_{S .2}^{1}$. Therefore, high-tech firms innovate more and the economy grows at a higher rate when there is knowledge licensing: $g_{\lambda}^{N E, S .1}>g_{\lambda}^{N E, S .2}$ and $g_{Y}^{N E, S .1}>g_{Y}^{N E, S .2}$

Total (consumer) welfare can be found using the household's life-time utility function, (30), and the fact that the economy is always on a balanced growth path. A monotonic transformation of the welfare function, which preserves only the relevant terms, is given by

$$
\bar{U}^{N E}=-\left[N^{\frac{\sigma}{\varepsilon-1}}\left(N L_{x}^{N E}\right)^{\sigma}\left(L_{Y}^{N E}\right)^{1-\sigma}\right]^{-(\theta-1)} \frac{1}{(\theta-1) \sigma g_{\lambda}^{N E}+\rho} .
$$

Proposition 2. Welfare is higher when there is knowledge licensing than when there are knowledge spillovers.

In a given instant, ceteris paribus the final output is lower when there is knowledge 
licensing than when there are knowledge spillovers according to (33) and (34). This result then holds because welfare increases with the growth rate of final output, $g_{Y}$, which is proportional to the growth rate of knowledge/productivity, $g_{\lambda} \cdot{ }^{11}$ For brevity, hereafter I solely discuss the results for $g_{\lambda}$ while keeping in mind that $g_{Y}$ is proportional to it.

Corollary 1. In both $S .1$ and S.2 setups, the growth rate of knowledge/productivity $g_{\lambda}$ increases with the elasticity of substitution between high-tech goods $\varepsilon$ and the number of high-tech firms $N$. Moreover, it is a concave function of $\varepsilon$ and $N$.

The driver behind these results are the relative price distortions, which are due to price setting by high-tech firms. These distortions increase the demand for labor in final goods production. Increasing the elasticity of substitution and/or the number of firms reduces these distortions and motivates final goods producers to substitute (a basket of) high-tech goods for labor. Higher demand for high-tech goods and higher amount of available labor increase the incentives of high-tech firms to conduct R\&D in line with (24). This increases $g_{\lambda}$.

The next section compares these decentralized equilibrium results with the first best allocations and growth rates.

\section{Social Optimum}

The hypothetical Social Planner selects the paths of quantities so as to maximize the lifetime utility of the household. The Social Planner solves the following problem:

$$
\begin{aligned}
& \max _{L_{x}, L_{r}}\left\{\int_{0}^{+\infty} \frac{C_{t}^{1-\theta}-1}{1-\theta} \exp (-\rho t) d t\right\} \\
& \text { s.t. } \\
& C=\left(N^{\frac{\varepsilon}{\varepsilon-1}} \lambda L_{x}\right)^{\sigma}\left[L-N\left(L_{x}+L_{r}\right)\right]^{1-\sigma}, \\
& \dot{\lambda}=\xi \lambda N L_{r}, \\
& \lambda(0)>0 .
\end{aligned}
$$

The following proposition offers the Social Planner's allocations and growth rates, where $S P$ superscript is used to make a distinction between these outcomes and the decentralized equilibrium outcomes.

Proposition 3. The Social Planner chooses labor force allocations so that the economy,

\footnotetext{
${ }^{11}$ Appendix E.5 shows that in a second generation growth model welfare can be lower when there is knowledge licensing than when there are knowledge spillovers. This holds because the growth rate of final output in such a model does not depend on innovation incentives and allocations.
} 
where there is "no entry", makes a discrete jump to a balanced growth path, where

$$
\begin{aligned}
& N L_{r}^{N E, S P}=\frac{1}{\xi} \frac{\xi \sigma L-\rho}{\theta \sigma}, \\
& N L_{x}^{N E, S P}=\sigma\left(L-N L_{r}^{N E, S P}\right), \\
& L_{Y}^{N E, S P}=L-N L_{x}^{N E, S P}-N L_{r}^{N E, S P}
\end{aligned}
$$

and

$$
\begin{aligned}
& g_{Y}^{N E, S P}=\sigma g_{\lambda}^{N E, S P}, \\
& g_{\lambda}^{N E, S P}=\frac{\xi \sigma L-\rho}{\theta \sigma} .
\end{aligned}
$$

The Social Planner necessarily innovates if $\xi \sigma L>\rho$, which holds as long as (31) holds since $\sigma>D$. As in decentralized equilibrium, this inequality states that the benefit from R\&D outweighs its cost.

Corollary 2. In decentralized equilibrium, the economy innovates less than is socially optimal and therefore grows at a lower rate: $g_{\lambda}^{N E, S P}>g_{\lambda}^{N E, S .1}$. Moreover, it fails to have socially optimal labor force allocations.

The drivers behind these results are the relative price distortions and knowledge spillovers in the S.2 case. Due to these distortions final goods producers substitute labor for high-tech goods, which lowers the output of high-tech firms and the number of researchers these firms hire. The spillovers in $R \& D$ have an effect of similar direction. If such spillovers are present then high-tech firms do not fully internalize the returns on $\mathrm{R} \& \mathrm{D}$, which reduces their incentives to invest in $\mathrm{R} \& \mathrm{D}$.

The deviation of $D$ from $\sigma$ summarizes the differences among socially optimal and decentralized equilibrium growth rates, and labor force allocations which stem from the relative price distortions. It is easy to notice that for sufficiently high $N$

$$
\lim _{\varepsilon \rightarrow+\infty} D=\sigma .
$$

This equality holds because for sufficiently high $N$ the limiting case $\varepsilon=+\infty$ would imply perfect competition in the high-tech industry. According to (32)-(36) and (39)-(43), socially optimal and decentralized equilibrium allocations and growth rates would then coincide when there is knowledge licensing. This is because high-tech firms fully appropriate the benefits from accumulation of knowledge when there is knowledge licensing and there are no distortions in the market for knowledge. ${ }^{12}$

In such a limiting case, however, in decentralized equilibrium high-tech firms make

\footnotetext{
${ }_{12}$ At the limit when $\sigma=1$, allocations and growth in the decentralized equilibrium are welfare maximizing when there is knowledge licensing since there are no relative price distortions.
} 
no profits from the sale of their goods and have no market incentives to innovate. In this respect, if there are no subsidies that keep the profits of high-tech firms non-negative, the positive relationship between innovation and $\varepsilon$ holds, as long as high-tech firms have sufficient profits to cover the costs of R\&D. Profits of high-tech firms and $\varepsilon$ are inversely related. Once profits net of $R \& D$ expenditures are equal to zero, increasing $\varepsilon$ further reduces innovation to zero. The relationship between intensity of product market competition and innovation then resembles an "inverted-U" shape because of the concavity of the relationship between innovation and $\varepsilon$ and this discontinuity. Such a relation is consistent with Schumpeter's argument that firms need to be sufficiently large in order to innovate. Moreover, it is in line with the empirical findings of Aghion, Bloom, Blundell, Griffith, and Howitt (2005), and provides an alternative explanation for those findings.

\section{Entry Regime 2: Cost-free Entry}

From (13), (14), and (24) it follows that the profits of a high-tech firm are given by

$$
\pi=w L_{x} \bar{\pi}
$$

where

$$
\bar{\pi}=\frac{1}{e-1}-\frac{g_{\lambda}}{r-g_{q_{\lambda}}-\left(1-\alpha I_{S .2}^{1}\right) g_{\lambda}} .
$$

The economy is on a balanced growth path for a given $N$ according to Proposition 1. On the balanced growth path, it is straightforward to show that $\bar{\pi}$ is constant and declines with $N$. In order to have a meaningful equilibrium, I assume that the parameters are such that there exists $N \in(1,+\infty)$ where $\bar{\pi}=0$ in both S.1 and S.2 setups (e.g., $\varepsilon$ is sufficiently high).

The condition that endogenizes the number of high-tech firms is

$$
\bar{\pi}=0
$$

because entry into the high-tech industry entails no costs.

The number of high-tech firms, $N$, makes a discrete jump to the balanced growth path equilibrium level at $t=0$ given these assumptions and the above mentioned properties of $\bar{\pi}$. Therefore, in decentralized equilibrium with cost-free entry the economy is on a

balanced growth path for any $t>0$, where $\dot{N}=0$. Labor force allocations and growth rate of knowledge/productivity are given by (32)-(34) and (36), where $N$ is endogenous. It is determined from (27) and the following equation:

$$
e=\frac{\xi \sigma L\left[1+\alpha I_{S .2}^{1}+(\theta-1) \sigma\right]}{\xi \sigma L-\rho} .
$$


In both S.1 and S.2 setups, there is unique $N$ which satisfies this equation. ${ }^{13}$ It is straightforward to show that the equilibrium number of firms declines with $\varepsilon$. This is because higher $\varepsilon$ implies lower mark-ups, which reduces $\bar{\pi}$ for a given $N$. The growth rate of knowledge $g_{\lambda}$ does not depend on $\varepsilon$ and $N$ since the right-hand side of (45) does not depend on them. Therefore, higher $\varepsilon$ entails no dynamic gains but static losses in terms of $N$ in this setup. These losses reduce welfare because of the love-for-variety specification. ${ }^{14}$

Proposition 4. The growth rate of knowledge/productivity is higher when there is knowledge licensing than when there are knowledge spillovers among high-tech firms: $g_{\lambda}^{C F E, S .1}>$ $g_{\lambda}^{C F E, S .2}$. However, there are fewer high-tech firms when there is knowledge licensing than when there are knowledge spillovers among these firms: $N^{C F E, S .1}<N^{C F E, S .2}$.

The latter result holds because R\&D investments are fixed costs. High-tech firms invest more in $R \& D$ when there is knowledge licensing. The number of firms in equilibrium declines with these costs.

The reduction in the number of firms weakens competitive pressures and distorts allocations in this framework. It also implies a lower variety of goods. Therefore, it implies lower welfare because of love-for-variety in (2), and the following proposition holds.

Proposition 5. Depending on model parameters, welfare when there is knowledge licensing can be higher or lower than welfare when there are knowledge spillovers.

- Welfare is lower when there is knowledge licensing than when there are knowledge spillovers if $\alpha$ is close to 0.

The love-for-variety specification plays an essential role in these results. It is shown in the proof of Proposition 5 that it is the sole decisive factor for this welfare comparison if $\alpha$ is close to zero. Welfare then is lower when there is knowledge licensing than when there are knowledge spillovers because the number of high-tech firms and goods is lower. Further, eliminating the love-for-variety by dividing $Y$ to $N^{\frac{\sigma}{\varepsilon-1}}$ and setting $\theta=1$, it can be shown that welfare is necessarily higher when there is knowledge licensing for any $\alpha>0$. This result is confirmed for $\theta>1$ using numerical methods.

Similarly to the case when there is no entry, the decentralized equilibrium fails to have socially optimal allocations and growth rates. Given that entry entails no costs, it follows from Proposition 3 that the Social Planner selects labor force allocations and $N$

${ }^{13}$ If at $t=0$ the number of high-tech firms is higher than the number determined by $\bar{\pi}=0$ and $\varepsilon-1-\alpha-$ $(\theta-1) \sigma>0$ then high-tech firms will exit the market till this condition is satisfied. Considering such a setup, or exit of high-tech firms instead of entry, can support the zero entry costs assumption.

${ }^{14}$ Clearly, there are no welfare losses because of higher $\varepsilon$ if there is no love-for-variety. Moreover, the result that $e$ in (45) does not depend on $N$ and $\varepsilon$ can be repealed if, for example, high-tech firms have fixed operating costs. 
such that the economy makes a discrete jump to a balanced growth path. On this path labor force allocations and growth rate of knowledge $g_{\lambda}$ are given by (39)-(41) and (43) and $N=+\infty .^{15}$

Using (36), (45), and (43), it can be shown that the economy invests in R\&D less than is socially optimal in both S.1 and S.2 setups in decentralized equilibrium with costfree (endogenous) entry into the high-tech industry. Therefore, it grows at a lower than socially optimal rate. Further, it fails to have the socially optimal number of high-tech firms.

\section{Policy Inference}

In this section, I offer policies that if implemented in decentralized equilibrium lead to the first best outcome. I assume that there is knowledge licensing in decentralized equilibrium. This can amount to assuming that intellectual property rights regulation enforces excludability of knowledge and gives the bargaining power to the licensors. In this respect, such an action is one of the necessary policy instruments for increasing welfare in decentralized equilibrium in this model.

I assume that the set of policy instruments includes constant marginal transfers on the purchases of high-tech goods, $\tau_{x}$. It also includes lump-sum transfers to high-tech firms, $T_{\pi}$, and to households, $T$. The latter balances government expenditures.

From the final goods producer's problem it follows that under such a policy (6) and (7) need to be rewritten as

$$
\begin{aligned}
& x_{j}=X\left[\frac{P_{X}}{\left(1-\tau_{x}\right) p_{x_{j}}}\right]^{\varepsilon} \\
& P_{X} X=\left(1-\tau_{x}\right) \sum_{i=1}^{N} p_{x_{i}} x_{i} .
\end{aligned}
$$

In turn, $T$ and $T_{\pi}$ need to be added to the budget constraint of the household (1) and the profit function of high-tech firm $j$ (13), correspondingly.

It can be shown that, in symmetric equilibrium, labor force allocations are given by (32)-(34) where $I_{S .2}^{1}=0$ and

$$
D=\left[\left(1-\tau_{x}\right) \frac{1-\sigma}{\sigma} \frac{1}{b}+1\right]^{-1}
$$

Therefore, it is sufficient to equate labor force allocations to R\&D and high-tech goods production to their socially optimal counterparts in order to obtain socially optimal allocations and growth rates. Such an outcome can be achieved by subsidizing the purchases

\footnotetext{
${ }^{15}$ In order to solve the Social Planner's optimal control problem with first order conditions $C$ needs to be rescaled so that $C<+\infty$ at $t=0$ (i.e., $C$ needs to be divided to $N^{\frac{\sigma}{\varepsilon-1}}$ ).
} 
of high-tech goods and setting $\tau_{x}=1 / e$, which equates $D$ in (46) to $\sigma$.

In this setup, it is enough to subsidize the demand for high-tech goods because the returns on knowledge accumulation are fully appropriated when there is knowledge licensing. Clearly, this result stems from the rather idealized setting for the market of knowledge. Nevertheless, it implies that subsidies to in-house R\&D, which are commonly suggested in similar growth models (e.g., van de Klundert and Smulders, 1997), can be complemented or replaced with intellectual property rights regulation which enforces excludability of knowledge and gives the bargaining power to the licensors.

Although under this policy labor force allocations and growth rate of knowledge in decentralized equilibrium are equal to their socially optimal counterparts, welfare is not. In decentralized equilibrium, there is a lower number of high-tech firms/goods under the assumption that $\bar{\pi}=0$ at $N<+\infty .^{16}$ The policy instrument which can correct for this is $T_{\pi}$. It is straightforward to show that it is sufficient to set $T_{\pi}=w L_{x} \tau_{\pi}$, where $\tau_{\pi}$ is such that for any finite $N$ the profits of firms are greater than zero but for $N=+\infty$ profits are zero.

Corollary 3. $\tau_{\pi}$ is a subsidy and it is given by

$$
\tau_{\pi}=\frac{(\varepsilon-1) \frac{1}{\sigma}(\xi \sigma L-\rho)-[(\theta-1) \xi \sigma L+\rho]}{(\varepsilon-1)[(\theta-1) \xi \sigma L+\rho]} .
$$

This implies that entry into the high-tech industry needs to be subsidized. Such subsidies are in the spirit of welfare improving R\&D subsidies in the model of Romer (1990) to the extent that entry can be thought to be a result of $R \& D$ that generates new types of goods.

\section{Conclusions}

The model presented in this paper incorporates knowledge (patent) licensing into a stylized endogenous growth framework, where the engine of growth is high-tech firms' inhouse R\&D. The inference from this model suggests that, if there is knowledge licensing, high-tech firms innovate more and economic growth and welfare are higher than when there are knowledge spillovers among these firms. The results also suggest that innovation in the high-tech industry, as well as economic growth, increase with the intensity of competition and the number of firms in that industry.

If entry is endogenous and entails no costs, innovation in the high-tech industry, and economic growth, are again higher when there is knowledge licensing. However, this happens at the expense of a lower number of high-tech firms. Welfare then is not necessarily

\footnotetext{
${ }^{16}$ Clearly, the number of firms in decentralized equilibrium is equal to the socially optimal number of firms
} if $\bar{\pi}=0$ at $N=+\infty$. 
higher when there is knowledge licensing than when there are knowledge spillovers because of this and love-for-variety. If there is no love-for-variety, then knowledge licensing delivers higher welfare.

Increasing the intensity of competition reduces the number of high-tech firms. However, it does not affect allocations, innovation in the high-tech industry, and economic growth. Therefore, if there is no love-for-variety, increasing the intensity of competition reduces welfare in this setup.

Taken together, these results suggest that intellectual property regulation which facilitates excludability of knowledge and motivates knowledge licensing increases the rate of economic growth. It also increases welfare if the number of firms is fixed and/or there is no love-for-variety. It can reduce welfare when the number of firms is endogenous and there is love-for-variety.

A policy consisting of four instruments can be sufficient for achieving the first best outcome in decentralized equilibrium. The policy gives the bargaining power in the market for knowledge to the licensors so that they appropriate all the benefit from their R\&D. Further, it offsets the relative price distortions with subsidies on the purchases of high-tech goods. Finally, it subsidizes entry into the high-tech industry and uses nondistorting taxes to cover all these subsidies. 


\section{Acknowledgements}

I am indebted to Marc Bourreau, Byeongju Jeong, Michal Kejak, Anna Kochanova, Sergey Slobodyan, Sjak Smulders, Katrin Tinn, Evangelia Vourvachaki, Krešimir Žigić, and many colleagues for helpful comments. Earlier drafts of this paper have benefitted from the comments from participants at the Southern Economic Association Meetings in New Orleans (2015), the European Economic Association Meetings in Toulouse (2014), the Arnoldshain Seminar in Valencia (2014), the Conference on Growth and Business Cycles in Theory and Practice in Manchester (2014), the Economic Theory Seminar Series in University of Barcelona (2013), the Royal Economic Society Meetings in Egham (2013), and the Armenian Economic Association Meetings in Yerevan (2013). I gratefully acknowledge the financial support from the Spanish Ministry of Education and Science through grant ECO2015-66701-R, from the Generalitat of Catalonia through grant 2014SGR493, and from the Grant Agency of the Czech Republic through project P402/12/G097. All errors remaining in this text are the responsibility of the author. 


\section{Appendix - Proofs}

Proof of Proposition 1: The growth rates of quantities and prices which characterize the essential dynamics of this model can be obtained from the Euler equation, (2)-(7), (9), (14), and (15). These growth rates are

$$
\begin{aligned}
& g_{C}=g_{Y}, \\
& g_{C}=\frac{1}{\theta}(r-\rho), \\
& g_{Y}=\sigma g_{X}+(1-\sigma) g_{L_{Y}}, \\
& g_{X}=g_{x}, \\
& g_{Y}=g_{w}+g_{L_{Y}}, \\
& g_{x}=g_{\lambda}+g_{L_{x}}, \\
& g_{w}=g_{q_{\lambda}}+g_{\lambda} .
\end{aligned}
$$

Combining (24) with (14), (15), (23), (25), (28), (29), (47), and (48)-(53) gives a differential equation in $L_{r}$ :

$$
\begin{aligned}
\dot{L}_{r} & =\frac{L-N L_{r}}{N \theta} \\
& \times\left\{\left[(\theta-1) \sigma+\alpha I_{S .2}^{1}+D\right] \xi N L_{r}-(\xi D L-\rho)\right\},
\end{aligned}
$$

for both S.1 and S.2 setups.

Let parameter restriction (31) hold. The first term of the differential equation (54) is non-negative. Without that term, the characteristic root of the differential equation is positive, $\partial \dot{L}_{r} / \partial L_{r}>0$. This, together with a neoclassical production function of final goods (2), implies that there is a unique $L_{r}$ such that (54) is stable and $N L_{r}, N L_{x}, L_{Y} \in$ $(0, L)$ :

$$
L_{r}^{N E}=\frac{1}{\xi N} \frac{\xi D L-\rho}{(\theta-1) \sigma+\alpha I_{S .2}^{1}+D} .
$$

Combining this expression with the relations between $N L_{x}$ and $L_{Y}(25)$ and $N L_{x}$ and $N L_{r}$ (29) gives the equilibrium allocations of labor force (32)-(34). Given that allocations of labor force are constant from (47), (49), and (52) it follows that

$$
\begin{aligned}
& g_{C}^{N E}=g_{Y}^{N E}=g_{w}^{N E}=\sigma g_{X}^{N E}, \\
& g_{X}^{N E}=g_{x}^{N E}=g_{\lambda}^{N E},
\end{aligned}
$$

where $g_{\lambda}$ is given by (23). Therefore, in decentralized equilibrium with no entry the economy makes a discrete jump to a balanced growth path in both S.1 and S.2 setups, if (31) holds. 
Proof of Proposition 2: The households own the firms. Total (consumer) welfare can be derived using the expressions for final output and budget constraint. It is given by

$$
U=-\frac{\left[N^{\frac{\sigma}{\varepsilon-1}}\left(N L_{x}\right)^{\sigma} L_{Y}^{1-\sigma}\right]^{-(\theta-1)}}{\theta-1} \frac{1}{(\theta-1) \sigma g_{\lambda}+\rho}[\lambda(0)]^{-\sigma(\theta-1)}+\frac{1}{\rho} \frac{1}{\theta-1} .
$$

For further analysis, I consider the following positive monotonic transformation of $U$ :

$$
\begin{aligned}
\bar{U} & =(\theta-1)[\lambda(0)]^{\sigma(\theta-1)}\left(U-\frac{1}{\rho} \frac{1}{\theta-1}\right) \\
& =-\left[N^{\frac{\sigma}{\varepsilon-1}}\left(N L_{x}\right)^{\sigma} L_{Y}^{1-\sigma}\right]^{-(\theta-1)} \frac{1}{(\theta-1) \sigma g_{\lambda}+\rho} .
\end{aligned}
$$

To skip unnecessary notation, I set $I_{S .2}^{1} \equiv 1$ and rewrite

$$
\begin{aligned}
& N L_{r}^{N E}=\frac{1}{\xi} \frac{\xi D L-\rho}{(\theta-1) \sigma+\alpha+D}, \\
& N L_{x}^{N E}=D \frac{[(\theta-1) \sigma+\alpha] L+\frac{1}{\xi} \rho}{(\theta-1) \sigma+\alpha+D}, \\
& L_{Y}^{N E}=\frac{1-\sigma}{\sigma b} D \frac{[(\theta-1) \sigma+\alpha] L+\frac{1}{\xi} \rho}{(\theta-1) \sigma+\alpha+D} .
\end{aligned}
$$

The cases of knowledge licensing and spillovers then correspond to $\alpha=0$ and $\alpha>0$ in these expressions.

It is sufficient to consider the sign of the following derivative in order to compare welfare when there is knowledge licensing with welfare when there are knowledge spillovers:

$$
\frac{1}{\theta-1} \frac{1}{-\bar{U}} \frac{\partial \bar{U}}{\partial \alpha}=\sigma \frac{1}{N L_{x}} \frac{\partial N L_{x}}{\partial \alpha}+(1-\sigma) \frac{1}{L_{Y}} \frac{\partial L_{Y}}{\partial \alpha}+\frac{\sigma}{(\theta-1) \sigma g_{\lambda}+\rho} \frac{\partial g_{\lambda}}{\partial \alpha}
$$

If this expression is positive (negative) then welfare is lower (higher) when there is knowledge licensing than when there are knowledge spillovers.

It is straightforward to show that the sign of this derivative is equivalent to the sign of the following expression:

$$
-(\theta-1) \sigma \xi(\sigma-D) L-(\sigma-D) \rho-\alpha(\xi \sigma L-\rho)
$$

which is negative. Therefore, welfare is higher in case when there is knowledge licensing than when there are knowledge spillovers. 
Proof of Corollary 1: The partial derivatives of $g_{\lambda}^{N E}$ with respect to $\varepsilon$ and $N$ are given by

$$
\begin{aligned}
& \frac{\partial g_{\lambda}^{N E}}{\partial \varepsilon}=\frac{\partial D}{\partial \varepsilon} \frac{\partial}{\partial D} \frac{\xi D L-\rho}{(\theta-1) \sigma+\alpha I_{S .2}^{1}+D}, \\
& \frac{\partial g_{\lambda}^{N E}}{\partial N}=\frac{\partial D}{\partial N} \frac{\partial}{\partial D} \frac{\xi D L-\rho}{(\theta-1) \sigma+\alpha I_{S .2}^{1}+D} .
\end{aligned}
$$

From (26), (27), and the expression for $D$ it follows that

$$
\begin{aligned}
& \frac{\partial D}{\partial \varepsilon}=\left(1-\frac{1}{N}\right) \sigma \frac{(1-\sigma)}{(e-\sigma)^{2}}, \\
& \frac{\partial D}{\partial N}=\frac{\varepsilon-1}{N^{2}} \sigma \frac{1-\sigma}{(e-\sigma)^{2}} .
\end{aligned}
$$

Clearly, both these expressions are positive. In turn, the second term in the first order partial derivatives of $g_{\lambda}^{N E}$ is given by

$$
\frac{\partial}{\partial D} \frac{\xi D L-\rho}{(\theta-1) \sigma+\alpha I_{S .2}^{1}+D}=\frac{\xi L\left[(\theta-1) \sigma+\alpha I_{S .2}^{1}\right]+\rho}{\left[(\theta-1) \sigma+\alpha I_{S .2}^{1}+D\right]^{2}} .
$$

This is also positive. Therefore, $g_{\lambda}^{N E}$ increases with $\varepsilon$ and $N$.

The second order partial derivatives of $g_{\lambda}^{N E}$ with respect to $\varepsilon$ and $N$ are given by

$$
\begin{aligned}
\frac{\partial^{2} g_{\lambda}^{N E}}{\partial \varepsilon^{2}} & =\frac{\partial^{2} D}{\partial \varepsilon^{2}} \frac{\partial}{\partial D} \frac{\xi D L-\rho}{(\theta-1) \sigma+\alpha I_{S .2}^{1}+D}+\left(\frac{\partial D}{\partial \varepsilon}\right)^{2} \frac{\partial^{2}}{\partial D^{2}} \frac{\xi D L-\rho}{(\theta-1) \sigma+\alpha I_{S .2}^{1}+D}, \\
\frac{\partial^{2} g_{\lambda}^{N E}}{\partial N^{2}} & =\frac{\partial^{2} D}{\partial N^{2}} \frac{\partial}{\partial D} \frac{\xi D L-\rho}{(\theta-1) \sigma+\alpha I_{S .2}^{1}+D}+\left(\frac{\partial D}{\partial N}\right)^{2} \frac{\partial^{2}}{\partial D^{2}} \frac{\xi D L-\rho}{(\theta-1) \sigma+\alpha I_{S .2}^{1}+D},
\end{aligned}
$$

where

$$
\begin{aligned}
& \frac{\partial^{2} D}{\partial \varepsilon^{2}}=-2\left(1-\frac{1}{N}\right)^{2} \sigma \frac{(1-\sigma)}{(e-\sigma)^{3}}, \\
& \frac{\partial^{2} D}{\partial N^{2}}=-2\left[\frac{\varepsilon-1}{N^{3}} \sigma \frac{1-\sigma}{(e-\sigma)^{2}}+\left(\frac{\varepsilon-1}{N^{2}}\right)^{2} \sigma \frac{(1-\sigma)}{(e-\sigma)^{3}}\right], \\
& \frac{\partial^{2}}{\partial D^{2}} \frac{\xi D L-\rho}{(\theta-1) \sigma+\alpha I_{S .2}^{1}+D}=-2 \frac{\xi L\left[(\theta-1) \sigma+\alpha I_{S .2}^{1}\right]+\rho}{\left[(\theta-1) \sigma+\alpha I_{S .2}^{1}+D\right]^{3}} .
\end{aligned}
$$

This implies that $g_{\lambda}^{N E}$ is a concave function of $\varepsilon$ and $N$. 
Proof of Proposition 3: It is straightforward to show that the Social Planner's optimal choices for $L_{x}$ and $L_{r}$ and returns on $\mathrm{R} \& \mathrm{D}$ are given by

$$
\begin{aligned}
& N L_{x}=\sigma\left(L-N L_{r}\right), \\
& q_{\lambda} \xi N \lambda=\frac{(1-\sigma) N}{L-N\left(L_{x}+L_{r}\right)} C^{1-\theta}, \\
& \dot{q}_{\lambda}=q_{\lambda} \rho-\left(q_{\lambda} \xi N L_{r}+\sigma \lambda^{-1} C^{1-\theta}\right) .
\end{aligned}
$$

The optimal choice of $L_{x}$ (56) together with the labor market clearing condition (28) implies that

$$
N L_{x}=\frac{1}{1-\sigma} \sigma L_{Y}
$$

This relation is the counterpart of (25).

Using (57), the expression for the returns on $R \& D$ (58) can be rewritten as

$$
g_{q_{\lambda}}=\rho-\left[(1-\sigma) \xi N L_{r}+\xi \sigma L\right]
$$

Meanwhile, from (28), (37), (38), and (56)-(58) it follows that

$$
\begin{aligned}
& g_{L_{x}}=g_{L_{Y}}=-\frac{N \dot{L}_{r}}{L-N L_{r}}, \\
& g_{C}=\sigma\left(g_{\lambda}+g_{L_{x}}\right)+(1-\sigma) g_{L_{x}}, \\
& g_{\lambda}=\xi N L_{r}, \\
& g_{q_{\lambda}}=-g_{\lambda}-g_{L_{x}}-(\theta-1) g_{C} .
\end{aligned}
$$

Combining (60) and (61)-(64) gives a differential equation in $L_{r}$,

$$
\dot{L}_{r}=\frac{L-N L_{r}}{\theta N}\left[\theta \sigma \xi N L_{r}-(\xi \sigma L-\rho)\right]
$$

Without the first non-negative term this expression implies that $\partial \dot{L}_{r} / \partial L_{r}>0$. Therefore, there is a unique $L_{r}$ such that $(65)$ is stable and $N L_{r} \in(0, L)$ :

$$
N L_{r}^{N E, S P}=\frac{1}{\xi} \frac{\xi \sigma L-\rho}{\theta \sigma} .
$$

Combining (66) with (56) and (59) gives the socially optimal (interior) allocations of labor force (39)-(41).

Given that labor force allocations are constant from (30) and (61)-(64) it follows that $g_{Y}^{N E, S P}$ can be derived from (37):

$$
g_{Y}^{N E, S P}=\sigma g_{\lambda}^{N E, S P}
$$


where $g_{\lambda}^{N E, S P}$ is given by (43). Therefore, the Social Planner chooses the allocations so that the economy, where there is "no entry", makes a discrete jump to a balanced growth path.

Proof of Corollary 2: The comparison between $g_{\lambda}$ in decentralized equilibrium and socially optimal $g_{\lambda}$ is equivalent to the following comparison

$$
\frac{\xi D L-\rho}{(\theta-1) \sigma+D} * \frac{\xi \sigma L-\rho}{\theta \sigma}
$$

The left-hand side increases with $D$, which is lower than $\sigma$. Therefore, $g_{\lambda}^{N E, S P}>g_{\lambda}^{N E, S .1}$.

It is clear from (32)-(34) and (39)-(41) that the decentralized economy fails to have socially optimal labor force allocations.

Proof of Proposition 4: The perceived elasticity of substitution is given by (45) and $D=\sigma(e-1) /(e-\sigma)$. To prove this proposition I consider the partial derivative of $g_{\lambda}$ with respect to $\alpha$. It is given by

$$
\frac{\partial g_{\lambda}}{\partial \alpha}=\frac{(\theta-1) \sigma \xi L \frac{\partial D}{\partial \alpha}+\alpha I_{S .2}^{1} \xi L \frac{\partial D}{\partial \alpha}-(\xi D L-\rho) I_{S .2}^{1}+\rho \frac{\partial D}{\partial \alpha}}{\left[(\theta-1) \sigma+\alpha I_{S .2}^{1}+D\right]^{2}} .
$$

Therefore, the sign of $\partial g_{\lambda} / \partial \alpha$ is equivalent to the sign of

$$
(\theta-1) \sigma \xi L \frac{\partial D}{\partial \alpha}+\alpha I_{S .2}^{1} \xi L \frac{\partial D}{\partial \alpha}-(\xi D L-\rho) I_{S .2}^{1}+\rho \frac{\partial D}{\partial \alpha},
$$

where

$$
\begin{aligned}
& D=\frac{\xi \sigma L\left[\alpha I_{S .2}^{1}+(\theta-1) \sigma\right]+\rho}{\xi L\left[1-\sigma+\alpha I_{S .2}^{1}+(\theta-1) \sigma\right]+\rho}, \\
& \frac{\partial D}{\partial \alpha}=\frac{\xi L I_{S .2}^{1}(1-\sigma)(\xi \sigma L-\rho)}{\left\{\xi L\left[1-\sigma+\alpha I_{S .2}^{1}+(\theta-1) \sigma\right]+\rho\right\}^{2}} .
\end{aligned}
$$

Using these expressions and manipulating (67) gives the following expression:

$$
\xi L(1-\sigma)-\left\{\xi L\left[1-\sigma+\alpha I_{S .2}^{1}+(\theta-1) \sigma\right]+\rho\right\}
$$

which has a negative value. This implies that $g_{\lambda}$ declines with $\alpha$ and $g_{\lambda}^{C F E, S .1}>g_{\lambda}^{C F E, S .2}$.

In turn, $N^{C F E, S .1}<N^{C F E, S .2}$ since the left-hand side of (45) increases with $N$ and the right-hand side of (45) increases with $\alpha I_{S .2}^{1}$. 
Proof of Proposition 5: Total welfare is given by (55), where

$$
\begin{aligned}
N & =\frac{(\varepsilon-1)(\xi \sigma L-\rho)}{\varepsilon(\xi \sigma L-\rho)-\xi \sigma L\left[1+\alpha I_{S .2}^{1}+(\theta-1) \sigma\right]}, \\
D & =\frac{\xi \sigma L\left[(\theta-1) \sigma+\alpha I_{S .2}^{1}\right]+\rho}{\xi L\left[1-\sigma+\alpha I_{S .2}^{1}+(\theta-1) \sigma\right]+\rho}, \\
b & =\frac{\xi \sigma L\left[\alpha I_{S .2}^{1}+(\theta-1) \sigma\right]+\rho}{\xi \sigma L\left[1+\alpha I_{S .2}^{1}+(\theta-1) \sigma\right]} .
\end{aligned}
$$

The partial derivatives of $N, D$, and $b$ with respect to $\alpha$ are given by

$$
\begin{aligned}
\frac{\partial N}{\partial \alpha} & =N \frac{\xi \sigma L}{\varepsilon(\xi \sigma L-\rho)-\xi \sigma L\left[1+\alpha I_{S .2}^{1}+(\theta-1) \sigma\right]} \\
\frac{\partial D}{\partial \alpha} & =\frac{\xi L(1-\sigma)(\xi \sigma L-\rho)}{\left\{\xi L\left[1-\sigma+\alpha I_{S .2}^{1}+(\theta-1) \sigma\right]+\rho\right\}^{2}} \\
\frac{\partial b}{\partial \alpha} & =\frac{\xi \sigma L(\xi \sigma L-\rho)}{\left\{\xi \sigma L\left[1+\alpha I_{S .2}^{1}+(\theta-1) \sigma\right]\right\}^{2}} .
\end{aligned}
$$

To avoid unnecessary notation, I set $I_{S .2}^{1} \equiv 1$. The comparison of welfare between the cases of knowledge licensing and spillovers is equivalent to the sign of the following derivative:

$$
\begin{aligned}
\frac{1}{\theta-1} \frac{1}{-\bar{U}} \frac{\partial \bar{U}}{\partial \alpha} & =\frac{\sigma}{\varepsilon-1} \frac{1}{N} \frac{d N}{d \alpha}+\sigma \frac{1}{N L_{x}} \frac{d N L_{x}}{d \alpha} \\
& +(1-\sigma) \frac{1}{L_{Y}} \frac{d L_{Y}}{d \alpha}+\sigma \frac{1}{(\theta-1) \sigma g_{\lambda}+\rho} \frac{d g_{\lambda}}{d \alpha}
\end{aligned}
$$

This expression can be rewritten as

$$
\begin{aligned}
\frac{1}{\theta-1} \frac{1}{-\bar{U}} \frac{\partial \bar{U}}{\partial \alpha} & =\frac{\sigma}{\varepsilon-1} \frac{1}{N} \frac{\partial N}{\partial \alpha} \\
& +\left[\sigma \frac{1}{N L_{x}} \frac{\partial N L_{x}}{\partial D}+(1-\sigma) \frac{1}{L_{Y}} \frac{\partial L_{Y}}{\partial D}+\sigma \frac{1}{(\theta-1) \sigma g_{\lambda}+\rho} \frac{\partial g_{\lambda}}{\partial D}\right] \frac{\partial D}{\partial \alpha} \\
& +(1-\sigma) \frac{1}{L_{Y}} \frac{\partial L_{Y}}{\partial b} \frac{\partial b}{\partial \alpha} \\
& +\sigma \frac{1}{N L_{x}} \frac{\partial N L_{x}}{\partial \alpha}+(1-\sigma) \frac{1}{L_{Y}} \frac{\partial L_{Y}}{\partial \alpha}+\sigma \frac{1}{(\theta-1) \sigma g_{\lambda}+\rho} \frac{\partial g_{\lambda}}{\partial \alpha}
\end{aligned}
$$

The first term expresses the change of welfare that stems from the change in the number of firms. It represents the love-for-variety effect. It is positive since $N$ increases with $\alpha$. The second term expresses the change of welfare that stems from the change in competitive pressures on allocations of labor force. Competitive pressures increase with $\alpha$ since so does $N$, and the second term is positive. The third term accounts for the shift of labor force allocation in final goods production because of changes in competitive pressure in the high-tech industry. It is negative since higher $\alpha$ implies a higher number of firms 
and substitution of high-tech goods for labor in the final goods production. Finally, the last three terms account for changes of welfare because of innovation incentives in the high-tech industry. It has been shown that, in the case when there is no entry, the sum of the last three terms is negative (see the proof of Proposition 2).

I denote the sum of the second and third terms as $C P$ - competitive pressure. It is straightforward to show that it can be written as:

$$
\begin{aligned}
\frac{1}{(\xi \sigma L-\rho)(1-\sigma)} C P & =\left\{\frac{\xi L[1-\sigma+\alpha+(\theta-1) \sigma]+\rho}{\xi \sigma L[(\theta-1) \sigma+\alpha]+\rho} \frac{(\theta-1) \sigma+\alpha}{(\theta-1) \sigma+\alpha+D}\right. \\
& \left.+\frac{\sigma}{\xi D L(\theta-1) \sigma+(\alpha+D) \rho} \frac{\xi L[(\theta-1) \sigma+\alpha]+\rho}{(\theta-1) \sigma+\alpha+D}\right\} \\
& \times \frac{\xi L}{\{\xi L[1-\sigma+\alpha+(\theta-1) \sigma]+\rho\}^{2}} \\
& -\frac{1}{\xi \sigma L[\alpha+(\theta-1) \sigma]+\rho} \frac{1}{1+\alpha+(\theta-1) \sigma} .
\end{aligned}
$$

In turn, I use $I I$ - innovation incentives - to denote the sum of the last three terms.

It can be shown that around $\alpha=0$ the expression above becomes

$$
\frac{1}{(\xi \sigma L-\rho)(1-\sigma)} C P=\frac{1}{\xi \sigma L(\theta-1) \sigma+\rho} \frac{1}{1+(\theta-1) \sigma} \frac{\sigma \xi L-\rho}{(\theta-1) \sigma \xi L+\rho}
$$

and

$$
\frac{1}{(\xi \sigma L-\rho)(1-\sigma)} I I=-\frac{1}{\xi \sigma L(\theta-1) \sigma+\rho} \frac{1}{(\theta-1) \sigma \xi L+\rho} \frac{\xi \sigma L-\rho}{1+(\theta-1) \sigma} .
$$

Therefore, around $\alpha=0$ the partial derivative of $\bar{U}$ with respect to $\alpha$ is given by

$$
\frac{1}{\theta-1} \frac{1}{-\bar{U}} \frac{\partial \bar{U}}{\partial \alpha}=\frac{\sigma}{\varepsilon-1} \frac{1}{N} \frac{\partial N}{\partial \alpha}
$$

This means that, for small values of $\alpha$, the variation in welfare because of variation in $\alpha$ stems solely from the love-for-variety effect. This effect is positive. Therefore, welfare is higher when there are knowledge spillovers than when there is knowledge licensing among high-tech firms for small values of $\alpha$. Clearly, if the love-for-variety effect was absent then $\partial \bar{U} / \partial \alpha=0$ for small values of $\alpha$.

In what follows, I focus on the case of logarithmic instantaneous utility function setting $\theta=1$. In this case,

$$
\begin{aligned}
\frac{1}{(\xi \sigma L-\rho)(1-\sigma)} C P & =\left[\frac{\xi L(1-\sigma+\alpha)+\rho}{\xi \sigma L \alpha+\rho} \frac{\alpha}{\alpha+D}+\frac{\sigma}{(\alpha+D) \rho} \frac{\xi L \alpha+\rho}{\alpha+D}\right] \\
& \times \frac{\xi L}{\{\xi L(1-\sigma+\alpha)+\rho\}^{2}}-\frac{1}{\xi \sigma L \alpha+\rho} \frac{1}{1+\alpha},
\end{aligned}
$$


and

$$
\begin{aligned}
I I & =-\frac{\xi D L-\rho}{\alpha+D} \frac{\alpha(\xi \sigma L-\rho)+(\sigma-D) \rho}{(\alpha \xi L+\rho)(\alpha+D) \rho}, \\
D & =\frac{\xi \sigma L \alpha+\rho}{\xi L(1-\sigma+\alpha)+\rho} .
\end{aligned}
$$

Therefore, with some abuse of notation, (68) can be rewritten as

$$
\begin{aligned}
\frac{1}{\theta-1} \frac{1}{-\bar{U}} \frac{\partial \bar{U}}{\partial \alpha} & =\frac{\sigma}{\varepsilon-1} \frac{\xi \sigma L}{\varepsilon(\xi \sigma L-\rho)-\xi \sigma L(1+\alpha)} \\
& -\frac{\alpha \sigma(\xi \sigma L-\rho)(\xi \sigma L-\rho)}{(\xi \sigma L \alpha+\rho)(1+\alpha)^{2} \rho}
\end{aligned}
$$

Clearly, when there is no love-for-variety effect then $\partial \bar{U} / \partial \alpha<0$ for any value of $\alpha$ which is greater than 0 . Therefore, welfare is higher when there is knowledge licensing than when there are knowledge spillovers for $\alpha>0$ if there is no love-for-variety effect.

This result is confirmed using numerical methods. In the numerical exercise, the values of parameters were selected from the following intervals:

$$
\begin{aligned}
\rho & \in[0.01,0.09] ; \theta \in[1,10] ; \\
\varepsilon & \in[1.5,5] ; \sigma \in[0.01,0.99] ; \\
\alpha & \in[0.01,0.99] ; \xi L \in[0.01,0.99] .
\end{aligned}
$$

In this exercise, I form a multidimensional grid of parameter values using 10 equidistant points from each interval. I perform the exercise for those points from that multidimensional grid which satisfy parameter restriction $(31)$ and $N>1$.

In general, the sign of $\partial \bar{U} / \partial \alpha$ from (69) depends on model parameters. For example, it is positive (negative) for relatively small (large) values of $\varepsilon$ and $\alpha$. Therefore, the sign of $\partial \bar{U} / \partial \alpha$ when $\theta>1$ also depends on model parameters.

I perform a naive calibration exercise to pin-down the values of model parameters keeping $\theta=1$. I use 2-digit (NAICS) industry-level data for the US. The data come from the EU KLEMS database (release 2009, revision 2010). High-tech industries are NAICS 24, 29-25, and 64, and the sample period is 1977-2007.

To simplify the notation, I denote $\gamma=\rho / \xi \sigma L$ and rewrite (69) as

$$
\frac{1}{\theta-1} \frac{1}{-\bar{U}} \frac{\partial \bar{U}}{\partial \alpha}=\sigma \frac{(\alpha+\gamma) \gamma(1+\alpha)^{2}-\alpha(1-\gamma)^{2}(\varepsilon-1)[\varepsilon(1-\gamma)-(1+\alpha)]}{(\varepsilon-1)[\varepsilon(1-\gamma)-(1+\alpha)](\alpha+\gamma)(1+\alpha)^{2} \gamma}
$$

I set $\rho=0.01$. In order to calibrate $\sigma$, I use the share of real value added in high-tech industries out of total industrial output averaged over the sample period. This implies that $\sigma=0.1305$. Further, in order to calibrate $\alpha$, I use the growth rate of real value added 
in high-tech industries, averaged over the sample period. This implies that $g_{\lambda}=0.044$. I normalise the scale of the economy and set $\xi L=0.5$ so that the value of $\alpha$ is not extra-ordinarily high. The value of $\alpha$ is then 0.259 . This implies that the share of a firm's knowledge input in its R\&D process is 0.741 .

In order to pin-down $\varepsilon$, I set $N=10$. The elasticity of substitution between high-tech goods is then equal to 1.541. The numerator of (70) is then equal to 0.096. Therefore, under these parameter values welfare is lower when there is knowledge licensing than when there are knowledge spillovers. This result tends to be not sensitive to the value of $N$ as long as $N>2$. When, for example, $N=1.5$ then $\varepsilon=2.461$ and the numerator of $(70)$ is equal to -0.1236 . Therefore, in such a case welfare is higher when there is knowledge licensing than when there are knowledge spillovers.

Proof of Corollary 3: I use superscript $G O$ to denote decentralized equilibrium with government. Suppose that $\tau_{x}=1 / e$ so that allocations of labor force in decentralised equilibrium coincide with the socially optimal allocations. The subsidy/tax rate $\tau_{\pi}$ can be derived from zero profit condition $\bar{\pi}^{G O}=0$ where

$$
\begin{aligned}
& \bar{\pi}^{G O}=\frac{1}{\varepsilon-1}-\frac{N L_{r}^{S P}}{N L_{x}^{S P}}+\tau_{\pi}, \\
& \frac{N L_{r}^{S P}}{N L_{x}^{S P}}=\frac{1}{\sigma} \frac{\xi \sigma L-\rho}{(\theta-1) \xi \sigma L+\rho} .
\end{aligned}
$$

Therefore,

$$
\begin{aligned}
\tau_{\pi} & =\frac{N L_{r}^{S P}}{N L_{x}^{S P}}-\frac{1}{\varepsilon-1} \\
& =\frac{(\varepsilon-1) \frac{1}{\sigma}(\xi \sigma L-\rho)-[(\theta-1) \xi \sigma L+\rho]}{[(\theta-1) \xi \sigma L+\rho](\varepsilon-1)} .
\end{aligned}
$$

The assumption that $\bar{\pi}=0$ holds at $N \in(1,+\infty)$ implies the following parameter restriction:

$$
\varepsilon>\frac{\xi \sigma L\left[1+\alpha I_{S .2}^{1}+(\theta-1) \sigma\right]}{\xi \sigma L-\rho} .
$$

This parameter restriction implies that $\tau_{\pi}>0$ so that it is a subsidy.

Under this policy, the budget constraint of the household is given by

$$
C=N \pi+w L-N T_{\pi}-\tau_{x} N p_{x} x
$$

It is straightforward to show that the right-hand side of this expression is equal to $Y$.

It has to be that $Y^{G O}=Y^{S P}$ since under this policy labor force allocations are equal to the socially optimal allocations and $N=+\infty$. This implies that $U^{G O}=U^{S P}$. 


\section{Appendix - Extensions}

\section{Appendix E.1}

In this section, I present a setup where high-tech firms cooperate in R\&D and select optimal rules for $R \& D$ so as to maximise joint profits. High-tech firms later compete in the product market. I call this case CO - R\&D cooperation.

I offer below the setup of the high-tech industry and the optimization problem of high-tech firms in the stage of R\&D cooperation.

R\&D Cooperation: Each high-tech firm has its knowledge. At the R\&D cooperation stage high-tech firms establish a research joint venture where they pool their knowledge and jointly hire researchers. In a "laboratory," a group of researchers combines the knowledge of different firms in order to produce a better one for each firm. There are as many laboratories (or different knowledge production processes) as there are high-tech firms. This research joint venture takes into account the effect of the accumulation of one type of knowledge on the accumulation of other types of knowledge. ${ }^{17}$

In such a case, high-tech firms take (14) and initial values of $\lambda$ as given and jointly solve the following optimal problem:

$$
\begin{aligned}
& \max _{N L_{r}}\left\{\int_{\bar{t}}^{+\infty} \sum_{i=1}^{N} \pi_{j}(t) \exp \left[-\int_{\bar{t}}^{t} r(s) d s\right] d t\right\} \\
& \text { s.t. } \\
& \sum_{i=1}^{N} \pi_{j}=\sum_{i=1}^{N}\left(p_{x_{i}} \lambda_{i}-w\right) L_{x_{i}}-w N L_{r}, \\
& x_{j}=\lambda_{j} L_{x_{j}}, \\
& \dot{\lambda}_{j}=\xi\left(\sum_{i=1}^{N} \lambda_{i}^{\alpha}\right) \lambda_{j}^{1-\alpha} L_{r_{j}} .
\end{aligned}
$$

The optimal rules for $R \& D$ that follow from this problem are

$$
\begin{aligned}
& w=q_{\lambda_{j}} \frac{\dot{\lambda}_{j}}{L_{r_{j}}} \\
& \frac{\dot{q}_{\lambda_{j}}}{q_{\lambda_{j}}}=r-\left(\sum_{j=1}^{N} \frac{e_{j}-1}{e_{j}} \frac{p_{x_{j}}}{q_{\lambda_{j}}} L_{x_{j}}+\frac{\partial \dot{\lambda}_{j}}{\partial \lambda_{j}}\right),
\end{aligned}
$$

\footnotetext{
${ }^{17}$ An alternative cooperation mode is that high-tech firms in the R\&D stage jointly hire researchers and produce the same knowledge for all. In such a case the R\&D process is $\dot{\lambda}=\xi \lambda N L_{r}$. It can be easily shown that the decentralised equilibrium outcome of this cooperation mode is no different than the outcome of the cooperation mode offered in this section.
} 
where

$$
\begin{aligned}
\frac{\partial \dot{\lambda}_{j}}{\partial \lambda_{j}} & =\xi L_{r_{j}} \\
& \times\left\{1+(1-\alpha)\left(\sum_{i=1, i \neq j}^{N} \frac{\lambda_{i}}{\lambda_{j}}\right)^{\alpha}+\alpha\left[\sum_{i=1, i \neq j}^{N}\left(\frac{\lambda_{i}}{\lambda_{j}}\right)^{-(1-\alpha)} \frac{\partial \lambda_{i}}{\partial \lambda_{j}}\right]\right\},
\end{aligned}
$$

and

$$
\frac{\partial \lambda_{i}}{\partial \lambda_{j}}=\frac{\partial \lambda_{i}}{\partial t} \frac{\partial t}{\partial \lambda_{j}}=\left(\frac{\lambda_{i}}{\lambda_{j}}\right)^{1-\alpha} \frac{L_{r_{i}}}{L_{r_{j}}} .
$$

The third term in the second line of (77) illustrates the effect of the accumulation of the $j$ th type of knowledge (the knowledge of high-tech firm $j$ ) on the accumulation of remaining types of knowledge.

In symmetric equilibrium, according to (74) the growth rate of knowledge is given by

$$
g_{\lambda}=\xi N L_{r}
$$

The rate of return on $\mathrm{R} \& \mathrm{D}$ can be derived from (14), (75)-(78). It is the same as (24) where $I_{S .2}^{1}=0$,

$$
g_{q_{\lambda}}=r-g_{\lambda}\left(\frac{L_{x}}{L_{r}}+1\right) .
$$

The growth rates of quantities and prices that characterise the essential dynamics of this model are given by (48)-(53).

Combining (24) with (14), (25), (28), (29), (47)-(53), (75), and (79) gives a differential equation in $L_{r}$ :

$$
\dot{L}_{r}=\frac{L-N L_{r}}{N \theta}\left\{[(\theta-1) \sigma+D] \xi N L_{r}-(\xi D L-\rho)\right\}
$$

which is the counterpart of (54).

Let $\theta \geq 1$ and (31) hold. Therefore, given that the first term of this differential equation is non-negative there is a unique $L_{r}$ such that (80) is stable and $N L_{r}, N L_{x}, L_{Y} \in$ $(0, L)$ :

$$
N L_{r}=\frac{1}{\xi} \frac{\xi D L-\rho}{(\theta-1) \sigma+D}
$$

Combining this expression with the relations between $N L_{x}$ and $L_{Y}(25)$ and $N L_{x}$ and $N L_{r}$ (29) and (79) gives the equilibrium allocations of labor force and growth rates of final output and knowledge. These coincide with (32)-(36), which means that knowledge licensing and R\&D cooperation deliver equivalent equilibrium outcomes. ${ }^{18}$

\footnotetext{
${ }^{18}$ This result does not hold if there is continuous entry into the high-tech industry as shown in Jerbashian (2014) and Jerbashian (2015).
} 


\section{Appendix E.2}

In this section, I relax, in two ways, the assumption that there are externalities within high-tech firms and present the main properties of the model. First I assume that there are decreasing returns to $R \& D$ at firm-level unless there is an exchange of knowledge among high-tech firms. Next, I assume that there are no externalities in high-tech firms and, as in the main text, returns on R\&D are constant even if there is no exchange of knowledge.

I have assumed that $N$ is a real number. If $N$ also changes continuously then in the sums in (10) and (11) each firm has zero size. Since $\lambda$ of each firm is finite, dropping firm $j$ or any finite number of firms from those sums makes no difference for the inference. If $N$ changes discretely (and each firm has unit size), then let $N>2$.

\section{Decreasing Returns to R\&D Within Firms}

I assume that if there is knowledge licensing, the $\mathrm{R} \& \mathrm{D}$ process of high-tech firm $j$ is given by

$$
\dot{\lambda}_{j}=\xi\left[\sum_{i=1, i \neq j}^{N}\left(u_{i, j} \lambda_{i}\right)^{\alpha}\right] \lambda_{j}^{1-\alpha} L_{r_{j}} .
$$

This is the counterpart of (10) where $u_{j, j} \equiv 0$. In turn, if there are knowledge spillovers the $R \& D$ process is given by (11) where

$$
\tilde{\Lambda}=\sum_{i=1, i \neq j}^{N} \lambda_{i}^{\alpha}
$$

Therefore, the counterpart of (18) and (22) is given by

$$
\frac{\partial \dot{\lambda}_{j}}{\partial \lambda_{j}}=\xi(1-\alpha)\left[\sum_{i=1, i \neq j}^{N}\left(\frac{u_{i, j} \lambda_{i}}{\lambda_{j}}\right)^{\alpha}\right] L_{r_{j}} .
$$

Clearly, these R\&D processes imply that if there is no exchange of knowledge among high-tech firms then the economy does not grow in the long-run.

Assuming symmetric equilibrium in the high-tech industry, the growth rate of knowledge can be rewritten as

$$
g_{\lambda}=\xi(N-1) L_{r}
$$

The rate of return on $R \& D$ can be obtained from the optimal rules of the high-tech firm (14), (15), and (17), (21), (83). It is given by (24). Combining (24) with (14), (15), 
(25), (28), (29), (47), (48)-(53) and (84) gives the counterpart of (54),

$$
\begin{aligned}
\dot{L}_{r} & =\frac{L-N L_{r}}{N \theta} \\
& \times\left\{\left[(\theta-1) \sigma+\alpha I_{S .2}^{1}+D\right] \xi \frac{N-1}{N} N L_{r}-\left(\xi D \frac{N-1}{N} L-\rho\right)\right\} .
\end{aligned}
$$

I assume that

$$
\xi D \frac{N-1}{N} L-\rho>0 .
$$

The stable and interior solution of this differential equation then is

$$
N L_{r}=\frac{1}{\xi} \frac{\xi D L-\frac{N}{N-1} \rho}{(\theta-1) \sigma+\alpha I_{S .2}^{1}+D} .
$$

Therefore, $g_{\lambda}$ is given by

$$
g_{\lambda}^{N E}=\frac{\xi D \frac{N-1}{N} L-\rho}{(\theta-1) \sigma+\alpha I_{S .2}^{1}+D} .
$$

The ratio $(N-1) / N$ appears in $g_{\lambda}$ since the size of a firm's knowledge relative to the market indicates the amount of knowledge which does not enter the R\&D process. The number of high-tech firms, $N$, then has two effects on innovation since it affects competitive pressures in the high-tech industry and this ratio. The latter effect is absent in S.1 and S.2 setups.

The comparative statics with respect to $\alpha I_{S .2}^{1}, N$, and $\varepsilon$ presented in the section Entry Regime 1: Barriers to Entry hold. Welfare is higher in S.1 than in S.2, and decentralised equilibrium does not deliver the first best outcomes.

When there is cost-free entry, the growth rate of productivity $g_{\lambda}$ that solves the zero profit condition (44) is given by

$$
g_{\lambda}=\frac{\rho}{e-1-\alpha I_{S .2}^{1}-(\theta-1) \sigma} .
$$

Using the Implicit Function Theorem and (86) it can be easily shown then that

$$
\begin{aligned}
& \frac{\partial N}{\partial \varepsilon}<0, \\
& N^{S .1}<N^{S .2} .
\end{aligned}
$$

However, in this case

$$
\begin{aligned}
& \frac{\partial g_{\lambda}^{C F E, S .1-2}}{\partial \varepsilon} \neq 0, \\
& g_{\lambda}^{C F E, S .1}<g_{\lambda}^{C F E, S .2} .
\end{aligned}
$$


The latter inequality holds in this case because higher $\alpha$ implies higher $N$ which has two effects on $g_{\lambda}$, through $D$ and $(N-1) / N$.

Welfare comparison is not straightforward since, even though $g_{\lambda}^{C F E}$ declines with $\alpha$, $N L_{x}$ declines with $(N-1) / N$.

\section{No Externalities Within Firms}

In this section, I assume that when there are knowledge spillovers the R\&D process is given by

$$
\dot{\lambda}_{j}=\xi\left(\lambda_{j}+\tilde{\Lambda} \lambda_{j}^{1-\alpha}\right) L_{r_{j}}
$$

where I assume that in equilibrium $\tilde{\Lambda}$ is given by (82).

From (87) it follows that (22) needs to be rewritten as

$$
\frac{\partial \dot{\lambda}_{j}}{\partial \lambda_{j}}=\xi\left[1+(1-\alpha) \sum_{i=1, i \neq j}^{N}\left(\frac{\lambda_{i}}{\lambda_{j}}\right)^{\alpha}\right] L_{r_{j}}
$$

The rate of return on $R \& D$ can be derived from the optimal rules of the high-tech firm (14), (15), and (17), (21), (87), and (88). In a symmetric equilibrium, it is given by

$$
g_{q_{\lambda}}=r-g_{\lambda}\left[\frac{L_{x}}{L_{r}}+\frac{1+(1-\alpha)(N-1)}{N}\right]
$$

Combining (89) with (14), (15), (23), (25), (28), (29), (47), and (48)-(53) gives the counterpart of (54),

$$
\dot{L}_{r}=\frac{L-N L_{r}}{N \theta}\left\{\left[(\theta-1) \sigma+D+\alpha \frac{N-1}{N}\right] \xi N L_{r}-(\xi D L-\rho)\right\} .
$$

Therefore, the stable solution of this differential equation is

$$
N L_{r}=\frac{1}{\xi} \frac{\xi D L-\rho}{(\theta-1) \sigma+D+\alpha \frac{N-1}{N}},
$$

and

$$
g_{\lambda}^{N E, S .2}=\frac{\xi D L-\rho}{(\theta-1) \sigma+D+\alpha \frac{N-1}{N}} .
$$

The ratio $(N-1) / N$ appears in these expressions since the size of a firm's knowledge relative to the market indicates the amount of knowledge which is not in the spillovers term. The number of high-tech firms, $N$, then has two effects on innovation since it affects competitive pressures in the high-tech industry and this ratio. The latter effect is absent in S.1 and S.2 setups.

Clearly, the comparative statics with respect to $\alpha I_{S .2}^{1}$ and $\varepsilon$ presented in the section Entry Regime 1: Barriers to Entry hold. Welfare is higher in S.1 than in S.2, and decen- 
tralised equilibrium does not deliver the first best outcomes. However, the derivative of $g_{\lambda}^{N E, S .2}$ with respect to $N$ depends on model parameters.

When there is cost-free entry, the growth rate of productivity $g_{\lambda}$ that solves the zero profit condition (44) is given by (86) where there is $\alpha(N-1) / N$ instead of $\alpha$. Using $g_{\lambda}$ from (86), the Implicit Function Theorem, and parameter restriction (71), it can be easily shown then that

$$
\begin{aligned}
& \frac{\partial N}{\partial \varepsilon}<0, \\
& N^{S .1}<N^{S .2}, \\
& \frac{\partial g_{\lambda}^{C F E, S .1-2}}{\partial \varepsilon} \neq 0, \\
& g_{\lambda}^{C F E, S .1}>g_{\lambda}^{C F E, S .2} .
\end{aligned}
$$

Welfare comparison is not straightforward and is omitted for brevity.

\section{Appendix E.3}

In this section, I offer a setup where knowledge can be licensed; however there are some knowledge spillovers.

I assume that the R\&D process is given by

$$
\dot{\lambda}_{j}=\xi\left[\sum_{i=1}^{N} \tilde{\lambda}_{i}\left(u_{i, j} \lambda_{i}\right)^{\alpha_{1}}\right] \lambda_{j}^{\alpha_{2}} L_{r_{j}}
$$

where for modelling knowledge spillovers, I assume that, in equilibrium,

$$
\tilde{\lambda}_{i}=\left(u_{i, j} \lambda_{i}\right)^{1-\alpha_{1}-\alpha_{2}}
$$

Moreover, I take

$$
\begin{aligned}
& 1-\alpha_{1}-\alpha_{2}<\alpha, \\
& \alpha_{1}<\alpha,
\end{aligned}
$$

in order to have lower magnitude of spillovers than in S.2 and fewer internalised returns on R\&D than in S.1.

From the optimal problem of high-tech firm $j$ it follows that the demand functions 
for labor force for production and R\&D are then given by

$$
\begin{aligned}
w & =\lambda_{j} p_{x_{j}}\left(1-\frac{1}{e_{j}}\right), \\
w & =q_{\lambda_{j}} \frac{\partial \dot{\lambda}_{j}}{\partial L_{r_{j}}}
\end{aligned}
$$

In turn, the returns on R\&D are given by

$$
\frac{\dot{q}_{\lambda_{j}}}{q_{\lambda_{j}}}=r-\left(\frac{e_{j}-1}{e_{j}} \frac{p_{x_{j}}}{q_{\lambda_{j}}} L_{x_{j}}+\frac{\partial \dot{\lambda}_{j}}{\partial \lambda_{j}}+\sum_{i=1, i \neq j}^{N} \frac{p_{u_{j, i} \lambda_{j}} u_{j, i}}{q_{\lambda_{j}}}\right),
$$

where

$$
\frac{\partial \dot{\lambda}_{j}}{\partial \lambda_{j}}=\xi \lambda_{j}^{\alpha_{2}-1} L_{r_{j}}\left[\alpha_{2} \sum_{i=1}^{N} \tilde{\lambda}_{i}\left(u_{i, j} \lambda_{i}\right)^{\alpha_{1}}+\alpha_{1} \tilde{\lambda}_{j} \lambda_{j}^{\alpha_{1}}\right],
$$

and the supply of and demand for knowledge are

$$
\begin{aligned}
& u_{j, i}=1, \forall i \neq j, \\
& p_{u_{i, j} \lambda_{i}}=q_{\lambda_{j}} \xi \alpha_{1} \tilde{\lambda}_{i}\left(u_{i, j} \lambda_{i}\right)^{\alpha_{1}-1} \lambda_{j}^{\alpha_{2}} L_{r_{j}}, \forall i \neq j .
\end{aligned}
$$

In a symmetric equilibrium, the returns on $R \& D$ and demand for knowledge can be rewritten as

$$
\begin{aligned}
& g_{q_{\lambda}}=r-g_{\lambda}\left(\frac{L_{x}}{L_{r}}+\alpha_{1}+\alpha_{2}\right), \\
& p_{u_{i, j} \lambda_{i}}=q_{\lambda_{j}} \xi \alpha_{1} L_{r_{j}}, \forall i \neq j .
\end{aligned}
$$

These are the counterparts of (24) and (19). They indicate that firms in this setup have lower returns on $\mathrm{R} \& \mathrm{D}$ than in $\mathrm{S} .1$ since $\alpha_{1}+\alpha_{2}>1-\alpha$, and this is because firms receive lower licensing fees since $\alpha_{1}<\alpha$.

Using (29), (48)-(53), (91) and (92) the returns on R\&D (93) can be rewritten as a differential equation in $L_{r}$,

$$
\dot{L}_{r}=\frac{L-N L_{r}}{N \theta}\left\{\left[(\theta-1) \sigma+D+1-\left(\alpha_{1}+\alpha_{2}\right)\right] \xi N L_{r}-(\xi D L-\rho)\right\},
$$

This differential equation is stable if

$$
N L_{r}=\frac{1}{\xi} \frac{\xi D L-\rho}{(\theta-1) \sigma+D+1-\left(\alpha_{1}+\alpha_{2}\right)}
$$

This implies that the economy immediately jumps to a balanced growth path. Labor force allocations and $g_{\lambda}$ can be found from (25), (29), and (90). The difference among these outcomes and (32)-(36) is summarised by the term $1-\left(\alpha_{1}+\alpha_{2}\right)$. The decentralised 
equilibrium inference from this setup is somewhere inbetween the inference from S.1 and S.2 setups because $\alpha>1-\left(\alpha_{1}+\alpha_{2}\right)>0$.

\section{Appendix E.4}

In this section, I present the main properties of the model if high-tech firms take into account the effect of their R\&D on the price of knowledge $p_{u_{j, i} \lambda_{j}}$. Further, I offer a policy which leads to socially optimal outcomes. ${ }^{19}$

The high-tech firms in this case internalise the demand (19). Therefore, the profit function of high-tech firm $j$ "at the stage" when it designs its supply of knowledge and $\mathrm{R} \& \mathrm{D}$ is

$$
\begin{aligned}
\pi_{j} & =p_{x_{j}} x_{j}-w\left(L_{x_{j}}+L_{r_{j}}\right) \\
& +\left[\alpha \xi \sum_{i=1, i \neq j}^{N} q_{\lambda_{i}}\left(u_{j, i} \lambda_{j}\right)^{\alpha} \lambda_{i}^{1-\alpha} L_{r_{i}}-\sum_{i=1, i \neq j}^{N} p_{u_{i, j} \lambda_{i}}\left(u_{i, j} \lambda_{i}\right)\right] .
\end{aligned}
$$

This implies that, everything else the same, (17) needs to be rewritten as

$$
\frac{\dot{q}_{\lambda_{j}}}{q_{\lambda_{j}}}=r-\left[\frac{e_{j}^{k}-1}{e_{j}^{k}} \frac{p_{x_{j}}}{q_{\lambda_{j}}} L_{x_{j}}+\frac{\partial \dot{\lambda}_{j}}{\partial \lambda_{j}}+\alpha^{2} \xi \sum_{i=1, i \neq j}^{N} \frac{q_{\lambda_{i}}\left(u_{j, i} \lambda_{j}\right)^{\alpha} \lambda_{i}^{1-\alpha} L_{r_{i}}}{q_{\lambda_{j}} \lambda_{j}}\right] .
$$

Therefore, in symmetric equilibrium the rate of return on $R \& D$ is

$$
g_{q_{\lambda}}=r-g_{\lambda}\left[\frac{L_{x}}{L_{r}}+1-\alpha(1-\alpha) \frac{N-1}{N}\right] \text {. }
$$

In this expression the third term in square brackets captures the adverse effect of higher $\mathrm{R} \& \mathrm{D}$ on the price of knowledge.

Combining (48)-(53), (29), and (95) gives the counterpart of (54),

$$
\begin{aligned}
\dot{L}_{r} & =\frac{L-N L_{r}}{N \theta} \\
& \times\left\{\left[(\theta-1) \sigma+D+\alpha(1-\alpha) \frac{N-1}{N}\right] \xi N L_{r}-(\xi D L-\rho)\right\} .
\end{aligned}
$$

\footnotetext{
${ }^{19} \mathrm{I}$ assume that price discrimination is not feasible. This is necessary in order to avoid the problem with determination of the price of durable goods (Coase, 1972). In this framework it can be supported, for example, by an assumption that the licensors have to license their entire knowledge (at a uniform price). Another assumption that could support this is that licensors rent (but not sell) their knowledge and cannot monitor its use.
} 
Therefore, in equilibrium labor force allocations and $g_{\lambda}$ are given by

$$
\begin{aligned}
& N L_{r}^{N E, M}=\frac{1}{\xi} \frac{\xi D L-\rho}{(\theta-1) \sigma+D+\alpha(1-\alpha) \frac{N-1}{N}}, \\
& N L_{x}^{N E, M}=D \frac{\left[(\theta-1) \sigma+\alpha(1-\alpha) \frac{N-1}{N}\right] L+\frac{1}{\xi} \rho}{(\theta-1) \sigma+D+\alpha(1-\alpha) \frac{N-1}{N}}, \\
& L_{Y}^{N E, M}=\frac{1-\sigma}{\sigma b} N L_{x}, \\
& g_{\lambda}^{N E, M}=\xi N L_{r}^{N E, M},
\end{aligned}
$$

where I use $M$ in order to indicate that the firms are price setters in the market for knowledge in the sense that they internalise the effect of $R \& D$ on the price of knowledge. If $N$ changes continuously then $\frac{N-1}{N}$ can be replaced by 1 in all these expressions.

Clearly, the comparative statics with respect to $\varepsilon$ presented in the section Entry Regime 1: Barriers to Entry hold. The decentralised equilibrium does not deliver the first best outcomes. The derivative of $g_{\lambda}^{N E, S .2}$ with respect to $N$ depends on model parameters. Comparing these results with (32)-(36) it is clear that for any given $N$

$$
g_{\lambda}^{N E, S .1}>g_{\lambda}^{N E, M}>g_{\lambda}^{N E, S .2}
$$

This implies that $\bar{U}^{N E, S .1}>\bar{U}^{N E, M}>\bar{U}^{N E, S .2}$.

When there is cost-free entry, the growth rate of productivity $g_{\lambda}$ which solves the zero profit condition (44) is given by (86) where there is $\alpha(1-\alpha)(N-1) / N$ instead of $\alpha$. Using $g_{\lambda}$ from (86), the Implicit Function Theorem, and parameter restriction (71), it can be easily shown then that

$$
\begin{aligned}
& \frac{\partial N}{\partial \varepsilon}<0, \\
& N^{C F E, S .1}<N^{C F E, M}<N^{C F E, S .2}, \\
& \frac{\partial g_{\lambda}^{C F E, M}}{\partial \varepsilon} \neq 0, \\
& g_{\lambda}^{C F E, S .1}>g_{\lambda}^{C F E, M}>g_{\lambda}^{C F E, S .2} .
\end{aligned}
$$

Welfare comparison is not straightforward and is omitted for brevity.

\section{Appendix E.5}

In this section, I incorporate population growth in the model presented in the main text, so that $\dot{L} / L=n>0$. As I show below, the model then becomes a semi-endogenous (second generation) growth model in the spirit of Jones (1995).

To incorporate population growth, I make several changes in the setup. I assume that, 
in case when there is licensing, the knowledge production function of high-tech firm $j$ is given by

$$
\dot{\lambda}_{j}=\xi \sum_{i=1}^{N}\left[\left(u_{i, j} \lambda_{i}\right)^{\alpha} \lambda_{j}^{1-\alpha}\right]^{\phi} L_{r_{j}}^{\gamma} \tilde{L}_{r}^{\psi-1}
$$

where $\gamma \in(0,1], \phi \geq 0, \psi \geq 0$, and $\tilde{L}_{r}$ denotes the average number of the researchers in the economy,

$$
\tilde{L}_{r}=\frac{1}{N} \sum_{i=1}^{N} L_{r_{i}}
$$

It is exogenous to high-tech firms' decisions.

When there are spillovers, I assume that the knowledge production function is given by

$$
\dot{\lambda}_{j}=\xi \tilde{\Lambda} \lambda_{j}^{(1-\alpha) \phi} L_{r_{j}}^{\gamma} \tilde{L}_{r}^{\psi-1}
$$

where

$$
\tilde{\Lambda}=\sum_{i=1}^{N} \lambda_{i}^{\alpha \phi}
$$

The remainder of the model is kept intact. Therefore, this setup coincides with the setup offered in the main text when there is no population growth and $\gamma=\phi=\psi=1$.

High-tech firm $j$ 's problem is given by

$$
V_{j}(\bar{t})=\max _{p_{x_{j}}, L_{r_{j}},\left\{u_{j, i}, u_{i, j}\right\}_{i=1 ;(i \neq j)}^{N}}\left\{\int_{\bar{t}}^{+\infty} \pi_{j}(t) \exp \left[-\int_{\bar{t}}^{t} r(s) d s\right] d t\right\}
$$

s.t.

(6), (9) and either (96) or (97),

where $\bar{t}$ is the entry date and

$$
\begin{aligned}
\pi_{j} & =p_{x_{j}} x_{j}-w\left(L_{x_{j}}+L_{r_{j}}\right) \\
& +\left[\sum_{i=1, i \neq j}^{N} p_{u_{j, i} \lambda_{j}}\left(u_{j, i} \lambda_{j}\right)-\sum_{i=1, i \neq j}^{N} p_{u_{i, j} \lambda_{i}}\left(u_{i, j} \lambda_{i}\right)\right] .
\end{aligned}
$$

It follows then that firm $j$ 's demands for labor for production and R\&D are given by (14) and (15). Moreover, when there is knowledge licensing, the returns on knowledge accumulation are given by

$$
\frac{\dot{q}_{\lambda_{j}}}{q_{\lambda_{j}}}=r-\left(\frac{e_{j}-1}{e_{j}} \frac{p_{x_{j}}}{q_{\lambda_{j}}} L_{x_{j}}+\frac{\partial \dot{\lambda}_{j}}{\partial \lambda_{j}}+\sum_{i=1, i \neq j}^{N} \frac{p_{u_{j, i} \lambda_{j}} u_{j, i}}{q_{\lambda_{j}}}\right),
$$

where

$$
\frac{\partial \dot{\lambda}_{j}}{\partial \lambda_{j}}=\xi \phi\left\{\lambda_{j}^{\phi-1}+(1-\alpha) \sum_{i=1, i \neq j}^{N} \frac{\left[\left(u_{i, j} \lambda_{i}\right)^{\alpha} \lambda_{j}^{1-\alpha}\right]^{\phi}}{\lambda_{j}}\right\} L_{r_{j}}^{\gamma} \tilde{L}_{r}^{\psi-1}
$$


The demand for and the supply of knowledge in this case are given by

$$
\begin{aligned}
& p_{u_{i, j} \lambda_{i}}=q_{\lambda_{j}} \xi \phi \alpha \frac{\left[\left(u_{i, j} \lambda_{i}\right)^{\alpha} \lambda_{j}^{1-\alpha}\right]^{\phi}}{u_{i, j} \lambda_{i}} L_{r_{j}}^{\gamma} \tilde{L}_{r}^{\psi-1}, \forall i \neq j, \\
& u_{j, i}=1, \forall i \neq j .
\end{aligned}
$$

When there are knowledge spillovers among high-tech firms, the returns on knowledge accumulation are given by (101) but

$$
p_{u_{j, i} \lambda_{j}}=0, \forall i
$$

and

$$
\frac{\partial \dot{\lambda}_{j}}{\partial \lambda_{j}}=\xi(1-\alpha) \phi \frac{\tilde{\Lambda} \lambda_{j}^{(1-\alpha) \phi}}{\lambda_{j}} L_{r_{j}}^{\gamma} \tilde{L}_{r}^{\psi-1} .
$$

In what follows I focus on a symmetric equilibrium and balanced growth path analysis. In symmetric equilibrium, the knowledge production function is given by

$$
\dot{\lambda}=\xi N \lambda^{\phi} L_{r}^{\gamma+\psi-1}
$$

When there is knowledge licensing, I use (14), (15), (101), (102), (103), and (104) to rewrite the returns on knowledge accumulation as

$$
g_{q_{\lambda}}=r-g_{\lambda}\left(\gamma \frac{L_{x}}{L_{r}}+\phi\right) .
$$

In turn, when there are knowledge spillovers, I use (14), (15), (101), (105), and (106) to rewrite the returns on knowledge accumulation as

$$
g_{q_{\lambda}}=r-g_{\lambda}\left[\gamma \frac{L_{x}}{L_{r}}+(1-\alpha) \phi\right]
$$

Therefore, in general, the returns on knowledge accumulation are given by

$$
g_{q_{\lambda}}=r-g_{\lambda}\left[\gamma \frac{L_{x}}{L_{r}}+\left(1-\alpha I_{S .2}^{1}\right) \phi\right]
$$

Clearly, this expression is identical to (24) when $\gamma=\phi=1$.

I use small letters with a hat to denote per-capita levels. Since there is population 
growth, the representative household solves the following problem.

$$
\begin{aligned}
& \max _{\hat{c}}\left\{\int_{0}^{+\infty} \frac{\hat{c}_{t}^{1-\theta}-1}{1-\theta} \exp (-(\rho-n) t) d t\right\} \\
& \text { s.t. } \\
& \dot{\hat{a}}=(r-n) \hat{a}+w-\hat{c} .
\end{aligned}
$$

The optimal rule that follows from the household's optimal problem is the standard Euler equation,

$$
g_{\hat{c}}=\frac{1}{\theta}(r-\rho) .
$$

This, together with budget constraint (110), describes the paths of the household's consumption and assets.

From (2), (3), (4), (9), (111), and goods market clearing condition (30) it follows that

$$
\begin{aligned}
& g_{\hat{y}}=\sigma g_{X}+(1-\sigma) g_{L_{Y}}-n, \\
& g_{X}=g_{x}, \\
& g_{\hat{y}}=g_{w}+g_{L_{Y}}-n, \\
& g_{x}=g_{\lambda}+g_{L_{x}}, \\
& r=\theta g_{\hat{c}}+\rho, \\
& g_{\hat{c}}=g_{\hat{y}} .
\end{aligned}
$$

From (15) and (107) it follows that on a balanced growth path the following conditions hold:

$$
\begin{aligned}
& g_{q_{\lambda}}=g_{w}-\phi g_{\lambda}-(\gamma+\psi-2) n, \\
& g_{\lambda}=\frac{\gamma+\psi-1}{1-\phi} n .
\end{aligned}
$$

This implies that in order for $g_{\lambda}$ to be positive on a balanced growth path it is sufficient to have $\gamma+\psi-1>0$ and $\phi<1$. To keep utility finite, I also require the following condition on the parameters of the model:

$$
(\rho-n)+(\theta-1) \sigma g_{\lambda}>0 .
$$

The system of equations (112)-(118) and (108) imply that on a balanced growth path the following condition holds:

$$
g_{\lambda} \frac{\gamma}{\beta} \frac{N L_{x}}{N L_{r}}=\left[(\theta-1) \sigma+\alpha I_{S .2}^{1} \phi\right] g_{\lambda}+(\gamma+\psi-2) n+\rho
$$


Labor shares in this equation are necessarily positive when $\gamma+\psi-1>0, \phi<1$, and (120) holds.

From (25) and the labor market clearing condition (28) it follows that

$$
N L_{x}=D\left(L-N L_{r}\right)
$$

where

$$
D=\frac{\sigma(e-1)}{e-\sigma} .
$$

Equations (121) and (122) solve for the balanced growth path values of the share of labor force allocated to the production of high-tech goods, $\omega_{L_{x}}=N L_{x} / L$, and the share of labor force allocated to $\mathrm{R} \& \mathrm{D}, \omega_{L_{r}}=N L_{r} / L$. These shares are given by

$$
\begin{aligned}
& \omega_{L_{x}}=\frac{D F(\alpha)}{D+F(\alpha)}, \\
& \omega_{L_{r}}=\frac{D}{D+F(\alpha)},
\end{aligned}
$$

where I use $F(\alpha)$ to denote

$$
F(\alpha)=\frac{\left[(\theta-1) \sigma+\alpha I_{S .2}^{1} \phi\right] g_{\lambda}+(\gamma+\psi-2) n+\rho}{g_{\lambda} \frac{\gamma}{\beta}} .
$$

In turn, the share of labor force allocated to the production of final goods is given by $(25)$,

$$
\omega_{L_{Y}}=\frac{1-\sigma}{\sigma} \frac{1}{b} \frac{D F(\alpha)}{D+F(\alpha)}
$$

where $b$ is given by $(26)$.

It is evident that $F(\alpha)$ increases with $\alpha$. Therefore, when there is knowledge licensing both $\omega_{L_{x}}$ and $\omega_{L_{Y}}$ are lower than when there are knowledge spillovers. This implies that output and consumption are lower when there is knowledge licensing. Such a result also holds in the model presented in the main text as discussed on page 13.

In turn, from (119) it follows that the growth rate of final output does not depend on $\alpha$ in this semi-endogenous growth model, and it is the same no matter if there is knowledge licensing or there are knowledge spillovers. This result holds because growth and innovation do not depend on labor allocations and incentives in this version of the model. ${ }^{20}$ It implies that balanced growth path welfare is lower when there is knowledge licensing than when there are knowledge spillovers. This is in contrast to the inference from the model presented in the main text. There, the growth rate of final output and welfare are higher when there is knowledge licensing than when there are knowledge

${ }^{20}$ This has served as a margin of criticism for semi-endogenous growth models (see, for example, Young, 1998, Jones, 1999). 
spillovers, even though $\omega_{L_{x}}$ and $\omega_{L_{Y}}$ are lower.

Further, I endogenize the number of firms assuming cost-free entry. The number of firms then is given by a zero profit condition, $\bar{\pi}=0$, which is equivalent to

$$
e=1+F(\alpha)
$$

The right-hand side of this expression increases with $\alpha$ and the left hand-side increases with $N$. Therefore, similarly to the model presented in the main text, the number of firms is lower when there is knowledge licensing than when there are knowledge spillovers (see Proposition 4).

On a balanced growth path the per-capita final output is given by

$$
\hat{y}=N^{\frac{\sigma}{\varepsilon-1}} \lambda^{\sigma} \omega_{L_{x}}^{\sigma} \omega_{L_{Y}}^{1-\sigma} .
$$

I denote an adjusted measure of output as

$$
\bar{y}=N^{\frac{\sigma}{\varepsilon-1}} \omega_{L_{x}}^{\sigma} \omega_{L_{Y}}^{1-\sigma}
$$

The balanced growth path welfare increases with $\bar{y}$ and depends on $\alpha$ only through $\bar{y}$. Clearly, the latter statement ignores possible differences because of the levels of $\lambda$. In this sense, I consider two countries which start at the same values of $\lambda$ and are on a balanced growth path, but they have different values of $\alpha$.

The derivative of $\bar{y}$ with respect to $\alpha$ is given by

$$
\frac{1}{\bar{y}} \frac{\partial \bar{y}}{\partial \alpha}=\frac{\sigma}{\varepsilon-1} \frac{1}{N} \frac{\partial N}{\partial \alpha}+\sigma \frac{1}{\omega_{L_{x}}}\left(\frac{\partial \omega_{L_{x}}}{\partial \alpha}+\frac{\partial \omega_{L_{x}}}{\partial e} \frac{\partial e}{\partial \alpha}\right)+(1-\sigma) \frac{1}{\omega_{L_{Y}}}\left(\frac{\partial \omega_{L_{Y}}}{\partial \alpha}+\frac{\partial \omega_{L_{Y}}}{\partial e} \frac{\partial e}{\partial \alpha}\right)
$$

It can be shown that in this expression, the first two terms are positive and the last term is equal to zero. Therefore, output increases with $\alpha$ and it is higher when there are knowledge spillovers than when there is knowledge licensing. This implies that balanced growth path welfare is also higher when there are knowledge spillovers. Such a result is in contrast to the results from the model offered in the main text. There is such a difference because in the model offered in the main text innovation and growth rate decline with $\alpha$, which is not the case here.

\section{Appendix E.6}

In this section, I incorporate dynamic entry of firms in the setup of the Appendix E.5. I show below that the model then becomes a scale-free (third generation) endogenous growth model in the spirit of Young (1998).

In particular, the model presented in this section bears a close resemblance to the 
model in Section III of Jones (1999). Firm entry is assumed to be proportional to population, which eliminates scale effects in this particular case because population growth results in more R\&D performing firms and increases the division of labor across the firms.

To incorporate firm entry, I make several changes in the setup of the model presented in Appendix E.5. I assume that there is free entry into the high-tech industry and at each instant a new firm arrives into the market according to the following entry rule (law of motion):

$$
\dot{N}=\eta N^{\delta} L
$$

where

$$
\begin{aligned}
& \delta=\frac{1}{\gamma+\psi-1}, \\
& \eta \geq 0
\end{aligned}
$$

Moreover, I assume that $\delta \leq 1$ (i.e., $\gamma+\psi-1 \geq 1$ ) and $\phi=1$ in the knowledge production function. ${ }^{21}$

The entry rule (124) implies that high-tech firms have no decision on entry. This is a simplification which allows the model to have a tractable inference. Alternatively, entrants could hire labor for entry. This would complicate the setup adding another variable that should be solved from the labor market clearing condition. Such a simplification is reasonable as long as that variable does not explicitly depend on $\alpha$. In this regard, it needs to be assumed that the value of any high-tech firm is greater than zero in order for the continual entry of firms to be justifiable. I maintain this assumption. This setup then prohibits the analysis of the effects of knowledge licensing and spillovers on the number of high-tech firms. Therefore, I do not carry it in this section.

Labor shares $\omega_{L_{Y}}=L_{Y} / L, \omega_{L_{x}}=N L_{x} / L$, and $\omega_{L_{r}}=N L_{r} / L$ are constant on a balanced growth path. According to (25), (28), (122) and (123), labor shares are constant when the perceived elasticity of substitution, $e$, is constant. The perceived elasticity of substitution depends on $N$ according to (27). Clearly, its variation because of firm entry can be ignored when the number of firms is very large. Hereafter, it is assumed that the number of firms is so large that the variation of $e$ can be ignored.

Further, to limit the growth effects of firm entry I assume that the production function of final output is given by

$$
Y=N^{-\chi} X^{\sigma} L_{Y}^{1-\sigma}
$$

where

$$
\frac{\sigma}{\varepsilon-1} \geq \chi \geq 0 .
$$

\footnotetext{
${ }^{21}$ The restrictions on the values of $\delta$ and $\phi$ help to eliminate the scale effects in this model. Admittedly, they are strong. The literature labels them as "knife-edge" conditions. Parameter restriction $\gamma+\psi-1 \geq 1$ can be relaxed assuming that $\xi$ declines with $N$.
} 
The remainder of the model is kept intact. Therefore, this setup coincides with the setup in Appendix E.5 when $\chi=\eta=0, V$ is not greater than zero for all firms (and potential firms), and $\phi \geq 0$. It coincides with the setup offered in the main text if, further, there is no population growth and $\gamma=\phi=\psi=1$.

I focus on a symmetric equilibrium and consider the balanced growth path of the model. From (3), (4), (9), (15), (30), (107), (111), (124), and (125) it follows that on the balanced growth path the following conditions hold:

$$
\begin{aligned}
& g_{X}=\frac{\varepsilon}{\varepsilon-1} g_{N}+g_{x}, \\
& g_{\hat{y}}=g_{w}, \\
& g_{x}=g_{\lambda}+n-g_{N}, \\
& g_{q_{\lambda}}=g_{w}+n-g_{N}-g_{\lambda}, \\
& g_{\hat{c}}=g_{\hat{y}},
\end{aligned}
$$

and

$$
\begin{aligned}
& g_{\lambda}=\xi \frac{L^{\gamma+\psi-1}}{N^{\gamma+\psi-2}} \omega_{L_{r}}^{\gamma+\psi-1}, \\
& r=\theta g_{\hat{c}}+\rho, \\
& g_{N}=\frac{1}{1-\delta} n, \\
& g_{\hat{y}}=\sigma\left(g_{X}-n\right)-\chi g_{N} .
\end{aligned}
$$

In turn, from (25), (122), and (108) it follows that

$$
\begin{aligned}
& \omega_{L_{Y}}=\frac{1-\sigma}{\sigma} \frac{1}{b} \omega_{L_{x}}, \\
& \omega_{L_{x}}=D\left(1-\omega_{L_{r}}\right), \\
& g_{q_{\lambda}}=r-g_{\lambda}\left(\gamma \frac{\omega_{L_{x}}}{\omega_{L_{r}}}+1-\alpha I_{S .2}^{1}\right) .
\end{aligned}
$$

I combine equations (126)-(137) to obtain

$$
g_{\hat{y}}=\sigma g_{\lambda}+\left(\frac{\sigma}{\varepsilon-1}-\chi\right) \frac{1}{1-\delta} n
$$

and

$$
\omega_{L_{r}}^{\gamma+\psi-1}\left[\gamma D \frac{1-\omega_{L_{r}}}{\omega_{L_{r}}}-\alpha I_{S .2}^{1}-(\theta-1) \sigma\right]=\Gamma,
$$

where

$$
\Gamma=\left(\xi \frac{L^{\gamma+\psi-1}}{N^{\gamma+\psi-2}}\right)^{-1}\left\{\left[(\theta-1)\left(\frac{\sigma}{\varepsilon-1}-\chi\right)+1\right] \frac{1}{1-\delta} n+(\rho-n)\right\}
$$


Equations (131), (138) and (139) solve for $g_{\lambda}, g_{\hat{y}}$, and the share of labor force in R\&D, respectively. The growth rates of $\lambda$, per capita output, and consumption increase with $\omega_{L_{r}}$ because $\gamma+\psi-1>0$. In turn, from (139) it can be shown that

$$
\frac{\partial \omega_{L_{r}}}{\partial \alpha}=\frac{\omega_{L_{r}}}{(\gamma+\psi-2) \gamma D \frac{1}{\omega_{L_{r}}}-(\gamma+\psi-1)\left[\gamma D+\alpha I_{S .2}^{1}+(\theta-1) \sigma\right]}
$$

The knowledge production function of this setup closely resembles the knowledge production function offered in the main text when $\gamma+\psi-1$ is close to 1 (from above). It is clear from this expression that $\omega_{L_{r}}$ and $g_{\hat{y}}$ decline with $\alpha$ when $\gamma+\psi-1$ is close to 1 (i.e., $\gamma+\psi-2$ is close to zero). Therefore, on the balanced growth path, at least for such parameter values, economic growth is higher when there is knowledge licensing than when there are knowledge spillovers.

For welfare comparisons, I consider two countries which start at the same values of $\lambda$ and $N$ (and $L$ ) and are on a balanced growth path, but they have different values of $\alpha$. It can be shown that on the balanced growth path a monotonic transformation of the welfare function is given by

$$
\bar{U}^{F E, B G P}=-\frac{\left(\omega_{L_{x}}^{\sigma} \omega_{L_{Y}}^{1-\sigma}\right)^{1-\theta}}{(\theta-1) \sigma g_{\lambda}+(\theta-1)\left(\frac{\sigma}{\varepsilon-1}-\chi\right) \frac{1}{1-\delta} n+\rho-n} .
$$

The derivative of $\bar{U}^{F E, B G P}$ with respect to $\alpha$ is given by

$$
\begin{aligned}
\frac{\partial \bar{U}^{F E, B G P}}{\partial \alpha} & =-(\theta-1) \bar{U}^{F E, B G P} \\
& \times \frac{\partial \omega_{L_{r}}}{\partial \alpha}\left[\frac{\sigma(\gamma+\psi-1)}{(\theta-1) \sigma g_{\lambda}+(\theta-1)\left(\frac{\sigma}{\varepsilon-1}-\chi\right) \frac{1}{1-\delta} n+\rho-n} \frac{g_{\lambda}}{\omega_{L_{r}}}-\frac{1}{1-\omega_{L_{r}}}\right] .
\end{aligned}
$$

If the expression in the second line is negative (positive) then welfare is higher (lower) when there is knowledge licensing than when there are knowledge spillovers. It is negative, for example, when $\gamma+\psi-1$ is close to 1 from above and $\sigma$ is close to 0 from above. Therefore, at least for such parameter values, the (balanced growth path) results of this model are similar to the results of the model presented in the main text. 


\section{References}

Aghion, P., N. Bloom, R. Blundell, R. Griffith, and P. Howitt (2005). Competition and innovation: An inverted-U relationship. Quarterly Journal of Economics 120(2), $701-728$.

Aghion, P. and P. Howitt (1992). A model of growth through creative destruction. Econometrica $60(2), 323-351$.

Anand, B. N. and T. Khanna (2000). The structure of licensing contracts. Journal of Industrial Economics 48(1), 103-135.

Arora, A. and A. Fosfuri (2003). Licensing the market for technology. Journal of Economic Behavior \& Organization 52(2), 277-295.

Arora, A. and A. Gambardella (2010). The market for technology. In B. H. Hall and N. Rosenberg (Eds.), Handbook of The Economics of Innovation, Volume 1, pp. 641678. North-Holland: Elsevier B.V.

Blundell, R., R. Griffith, and J. M. van Reenen (1999). Market share, market value and innovation in a panel of British manufacturing firms. Review of Economic Studies 66(3), $529-554$.

Coase, R. H. (1972). Durability and monopoly. Journal of Law and Economics 15(1), 143-149.

Faulí-Oller, R. and J. Sandonís (2002). Welfare reducing licensing. Games and Economic Behavior 41(2), 192-205.

Futagami, K. and T. Iwaisako (2007). Dynamic analysis of patent policy in an endogenous growth model. Journal of Economic Theory 132(1), 306-334.

Gallini, N. T. and R. A. Winter (1985). Licensing in the theory of innovation. RAND Journal of Economics 16(2), 237-252.

Grossman, G. M. and E. Helpman (1995). Technology and trade. In G. M. Grossman and K. Rogoff (Eds.), Handbook of International Economics (1 ed.), Volume 3. NorthHolland: Elsevier B.V.

Jerbashian, V. (2014). Knowledge licensing in a model of R\&D-driven endogenous growth. UB Economics Working Papers, wp. 2014/304.

Jerbashian, V. (2015). The telecommunications industry and economic growth: How the market structure matters. Economic Modelling 51, 515-523.

Jones, C. I. (1995). R\&D-based models of economic growth. Journal of Political Economy 103(4), 759-784.

Jones, C. I. (1999). Growth: With or without scale effects? American Economic Review $89(2), 139-144$.

Jones, C. I. (2005). Growth and ideas. In P. Aghion and S. N. Durlauf (Eds.), Handbook of Economic Growth, Volume 1B, pp. 1063-1111. North-Holland: Elsevier B.V.

Jones, C. I. and P. M. Romer (2010). The new Kaldor Facts: Ideas, institutions, popula- 
tion, and human capital. American Economic Journal: Macroeconomics 2(1), 224-245.

Judd, K. L. (1985). On the performance of patents. Econometrica 53(3), 567-586.

Katz, M. L. and C. Shapiro (1985). On the licensing of innovations. RAND Journal of Economics 16(4), 504-520.

O'Donoghue, T. and J. Zweimüller (2004). Patents in a model of endogenous growth. Journal of Economic Growth 9(1), 81-123.

Peretto, P. F. (1996). Sunk costs, market structure, and growth. International Economic Review 37(4), 895-923.

Peretto, P. F. (1998a). Technological change and population growth. Journal of Economic Growth 3(4), 283-311.

Peretto, P. F. (1998b). Technological change, market rivalry, and the evolution of the capitalist engine of growth. Journal of Economic Growth 3(1), 53-80.

Peretto, P. F. and S. Smulders (2002). Technological distance, growth and scale effects. Economic Journal 112(481), 603-624.

Rivera-Batiz, L. A. and P. M. Romer (1991). Economic integration and endogenous growth. Quarterly Journal of Economics 106(2), 531-555.

Romer, P. M. (1990). Endogenous technological change. Journal of Political Economy 98(5), 71-102.

Shapiro, C. (2001). Navigating the patent thicket: Cross licenses, patent pools, and standard setting. In Innovation Policy and the Economy, Volume 1, pp. 119-150. Cambridge, MA: MIT Press.

Smulders, S. and T. van de Klundert (1995). Imperfect competition, concentration and growth with firm-specific R\&D. European Economic Review 39(1), 139-160.

Tanaka, H., T. Iwaisako, and K. Futagami (2007). Dynamic analysis of innovation and international transfer of technology through licensing. Journal of International Economics 73(1), 189-212.

van de Klundert, T. and S. Smulders (1997). Growth, competition and welfare. Scandinavian Journal of Economics 99(1), 99-118.

Vives, X. (2008). Innovation and competitive pressure. Journal of Industrial Economics 56(3), 419-469.

Yang, G. and K. E. Maskus (2001). Intellectual property rights, licensing, and innovation in an endogenous product-cycle model. Journal of International Economics 1(53), $169-187$.

Young, A. (1998). Growth without scale effects. Journal of Political Economy 106(1), $41-63$. 